Journal of Business \& Management (COES\&RJ-JBM)

ISSN (E): 2306-7179 ISSN (P): 2306-8043

Publisher: Centre of Excellence for Scientific \& Research Journalism, COES\&RJ LLC Online Publication Date \& Issue: 1st July 2019, Vol.7, No.4, October 2019

https://doi.org/10.25255/jbm.2019.7.4.293.315

\title{
Reviewing the Concept of Innovation and it relationship with \\ Organizational Innovation: A Literature Review \\ Dr. Kholoud Sudqi Al-Louzi
}

An Independent Researcher, Amman, Jordan, Allouzi.kh.s.abdallah@hotmail.com

Abstract:

The adoption of innovation by the organizations is one of the basic concepts that play a positive role at the level of activity and life of the organization and continuity, especially at the present time where the competition for the development of the human element, considering the human being is the essence of the creative process, and the adoption of this concept requires a set of values and principles that seek to achieve creativity. The present study aimed at reviewing Arab and foreign studies on the concept of innovation and its relation to organizational innovation.

Keywords:

Innovation, Organizational Innovation, Literature Review

Citation:

Al-Louzi, Dr. Kholoud Sudqi (2019). Reviewing the Concept of Innovation and it relationship with Organizational Innovation: A Literature Review; Journal of Business \& Management (COES\&RJ-JBM) Vol.7, No.4, pp.293-315, https://doi.org/10.25255/jbm.2019.7.4.293.315. 


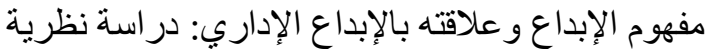

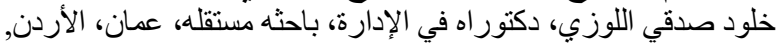 Allouzi.kh.s.abdallah@hotmail.com}

ملخص اعن م

إن اعتماد الإبداع من قبل المنظمات يعتبر من المفاهيم الأساسية التي تلعب دوراً إيجابياً على مستوى نشاط وحياة

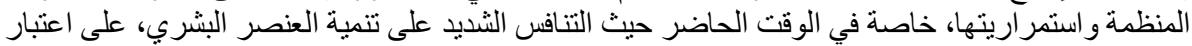

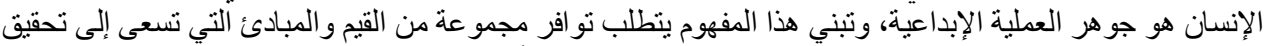

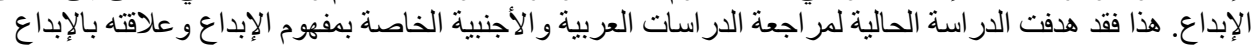

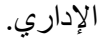

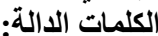

الإبداع، الإبداع الإدارية الإلة ، در اسة نظرية.

1

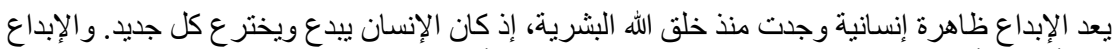

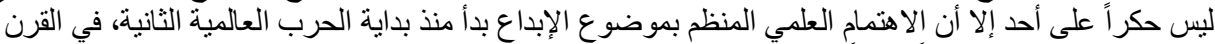

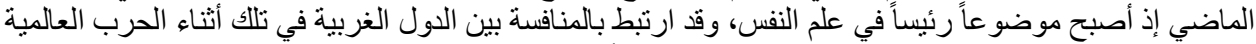

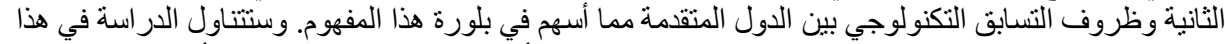

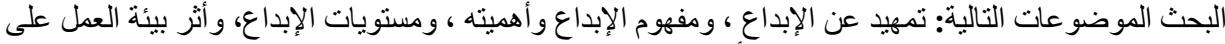

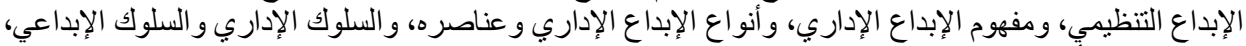

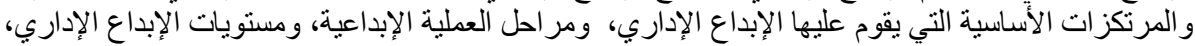

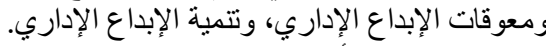
2 مفهوم الإبداع وأهميته:

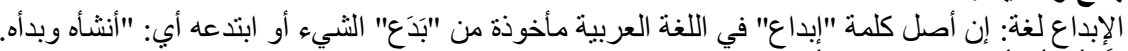

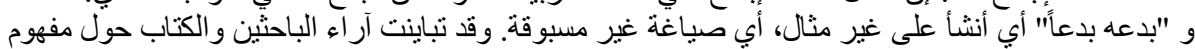

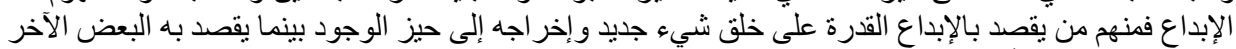

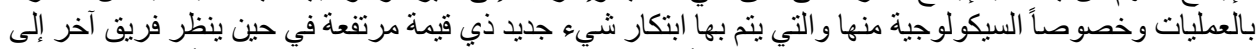

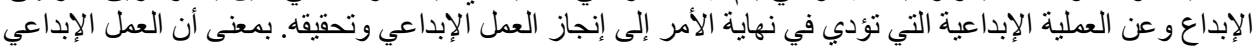

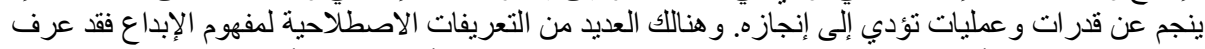

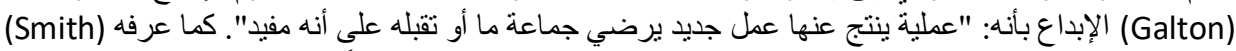

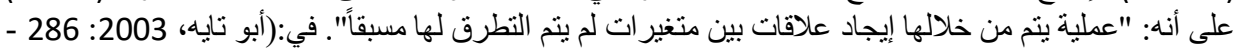

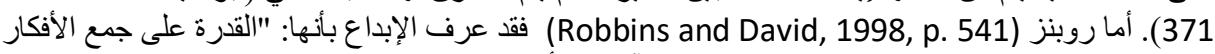

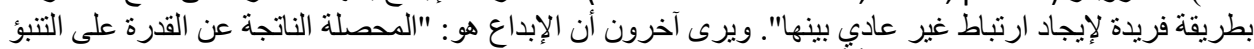

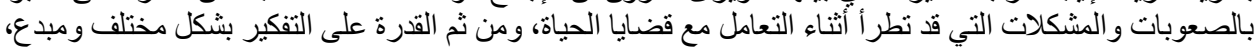

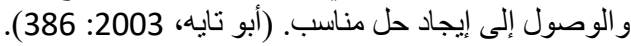

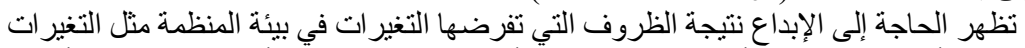

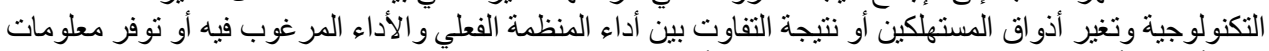

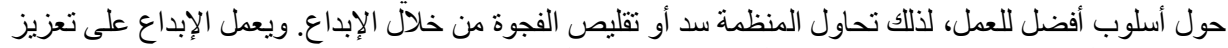

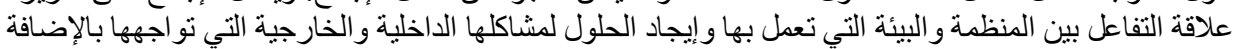

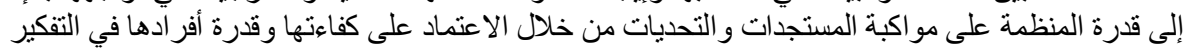

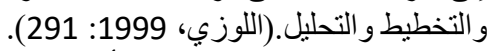

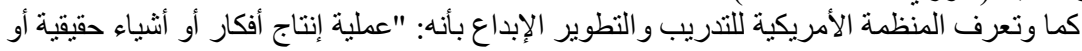

خيالية، ووضعها في طرق جديدة و مفيدة 2 American society for training and Development, 1989, أما المرسي (2001: 65) فقد عرف الإبداع "بأنه القدرة على تقديم شيء جديد القيد عما هو موجود بالفعل". وقد نظر العساف (1999) إلى الإبداع من أبعاد مختلفة على الإعلى النحو الآتي:

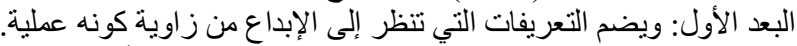

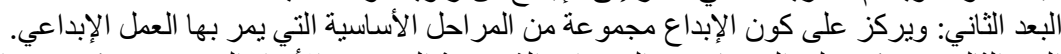

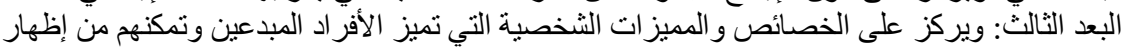

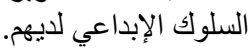
البعد الرابع: ويشمل الإبها التعريفات التي تركز على الإنتاج وحل المشكلات.

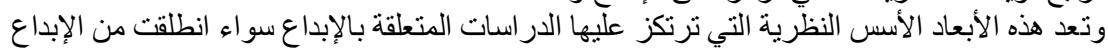

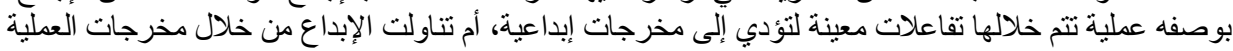


Reviewing the Concept of Innovation and it relationship with Organizational ...

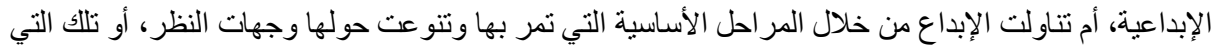

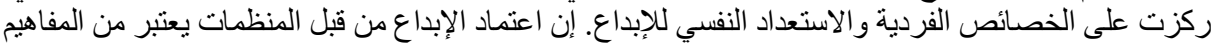

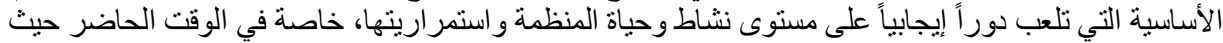

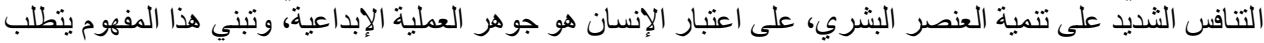

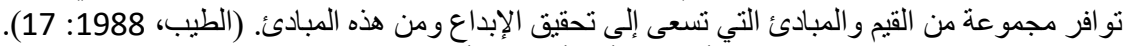

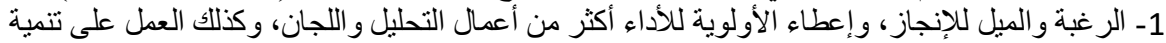

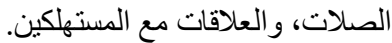
2- إعطاء الاستقلالية للوحدات، والأقسام الإدارية، مما يشجعها على التفكير والإبداع.

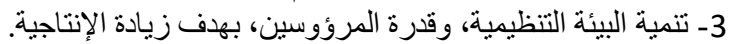

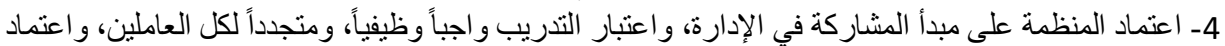
أنظمة موضو عية لغايات الأداء و التقييم. مما سبق يمكن تعريف الإبداع الإداري إلى أنه: "عبارة عن الوحدة المتكاملة لهجمو عة العو امل الذاتية

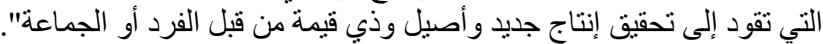

1/2

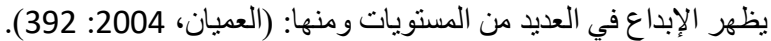

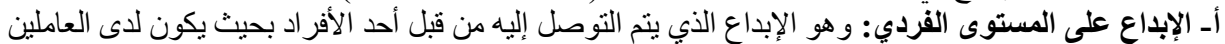

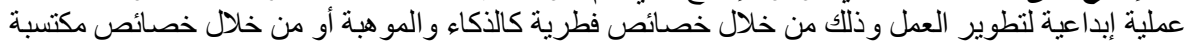
كالمثابرة و المرونة وحب المخاطرة والقدرة على التحليل وحل المشكلات و هذه الخصائص يمكن التدريب عليها

وتنميتها.

بـ الإبداع على مستوى الجماعة: و هو الإبداع الذي يتم التوصل إليه أو تقديمه من قبل الجماعة و إبداع الجماعة أكبر

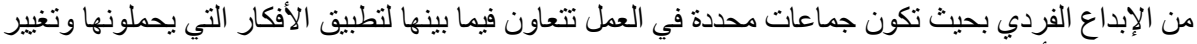

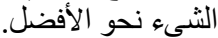

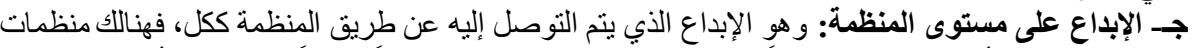

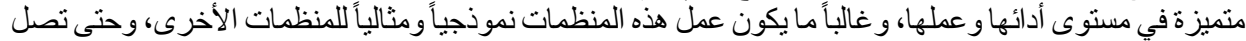

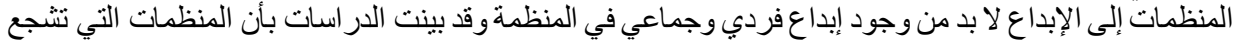

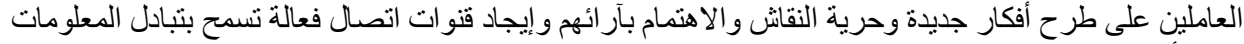

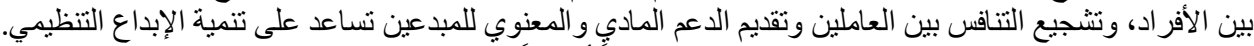

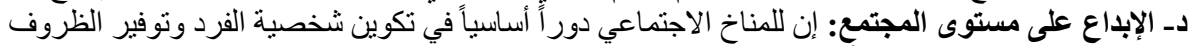

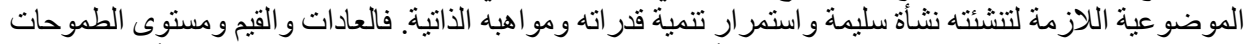

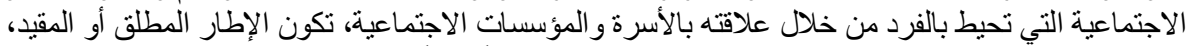

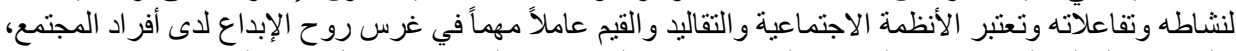

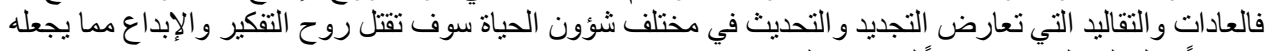
مجتمعاً يميل إلى الجمود ر افضـاً للإبداع و التجديد التيد.

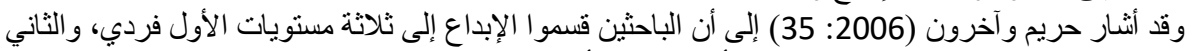

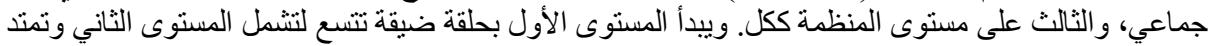

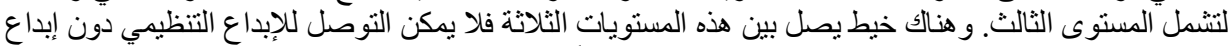

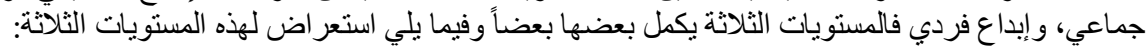
الإبداع على المستوى الفردي:

و هو الإبداع الذي يتم التوصل إليه من قبل أحد الأفر اد، الذي يتمتع بصفات أو خصائص أو سمات تميزه

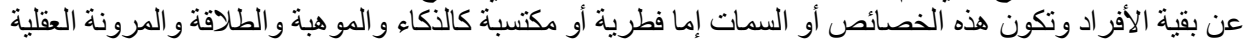

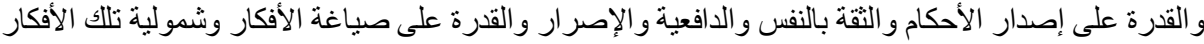

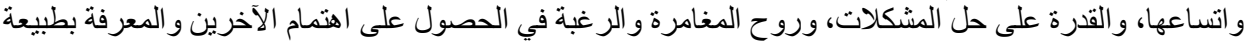

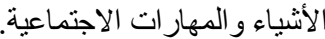

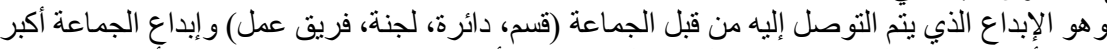

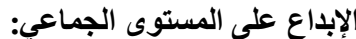

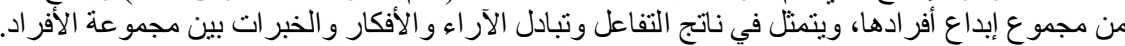

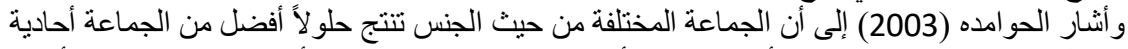

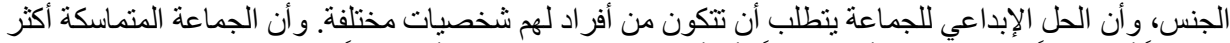
استعداداً أو حماساً من الجماعة الأقل تماسكاً وأن أفر اد الجماعة المنسجمة أكثر ميلاً للإبداع من الجماعة الجماع التي ليس بين 
أفر ادها انسجام وأن الجماعة حديثة التكوين تميل إلى الإبداع أكثر من الجماعة القديمة وكذلك حجم الجماعة فالإبداع

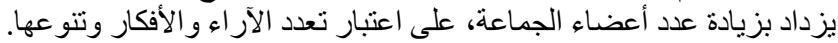
الإبداع على مستوى المنظمة:

إن مسألة الإبداع ليست مجرد نرف اليست أو مسألة كمالية، بل باتت أمر اً ضرورياً ملحاً لا غنى عنه، وخصوصاً إذا ما أر ادت هذه المنظمات تحقيق البقاء و الاستمر ارية في بيئة متنافسة.

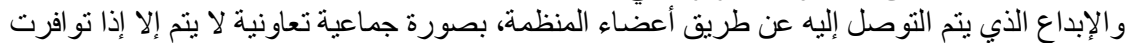

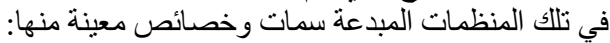

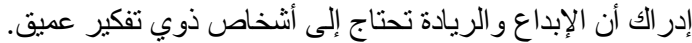

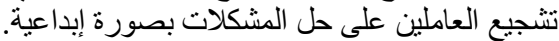
مشاركة العاملين في تقديم مقترحات للعمل لتنمية المهار ات واتئ والقدر ات الإبداعية لديهم.

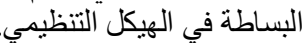
2/2 أثر بيئة العمل على الإبداع التنظيمي:

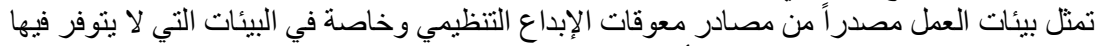

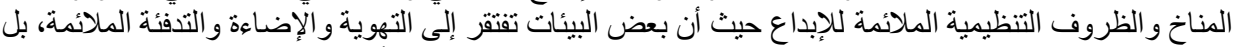

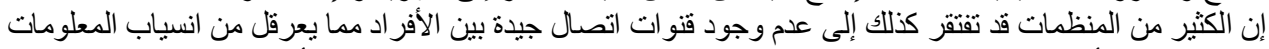

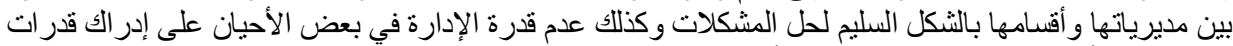

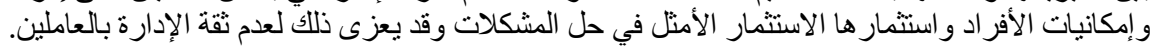

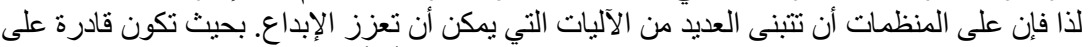

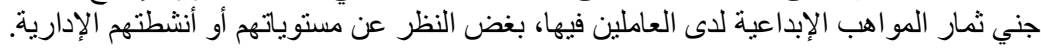

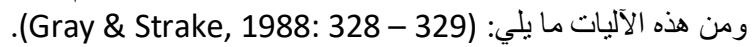
1- 2- التدعيم (مادياً ومعنوياً). 2- المساندة والتعضيد (بالعدد و الآلات و المختبرات وات ومر اكز البحوث).

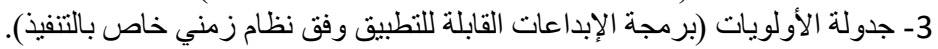
4- الموازنة بين التكييف وحرية العمل أي خلق حالة من التوازن بين حلئ حرية العمل و القو انين التي تعمل من خلالها و أكد كل من (Adair, 1985)، و(الدهان، 1989).، أنه بالإمكان زيادة الإبداع لدى الفرد العامل من خلال

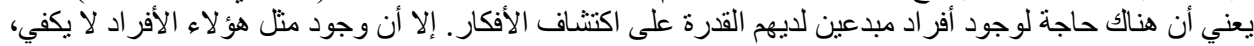

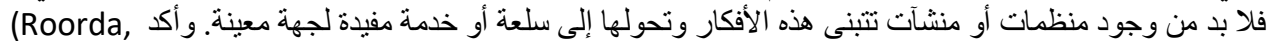
(2001 على ضرورة التركيز على ثلاثة أمور أساسية هي: التحسن المستمر في السلع المنتجة و الخدمة المقدمة،

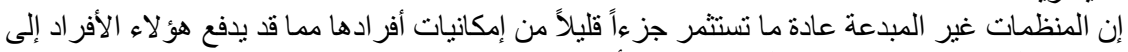
و الإبداع، وأهمية زيادة الكفاءة.

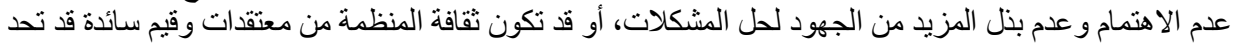

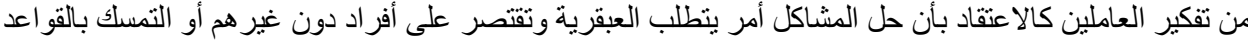

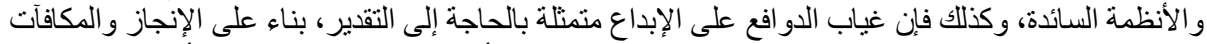

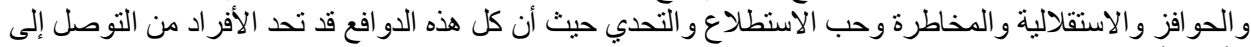
الأفكار أو الحلول الإبداعية. (الهمشري، 1994: 126).

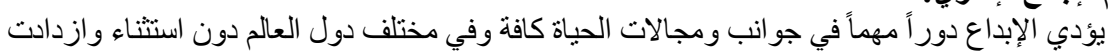

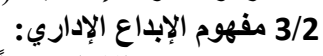

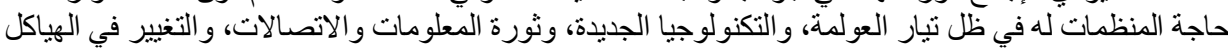

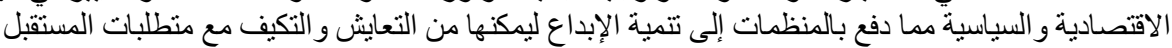

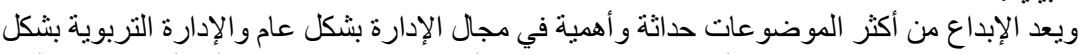

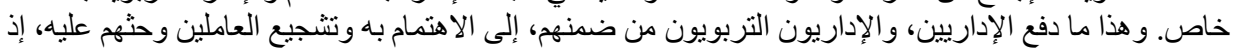


Reviewing the Concept of Innovation and it relationship with Organizational ...

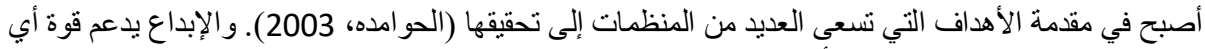

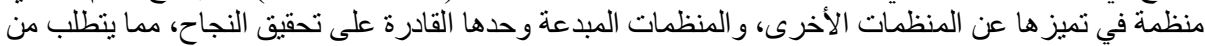

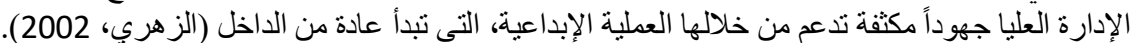

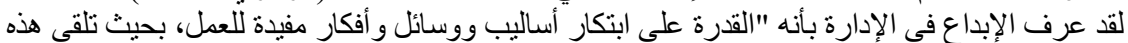

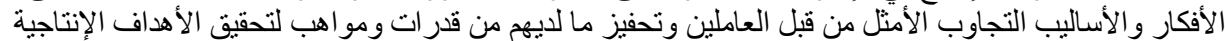

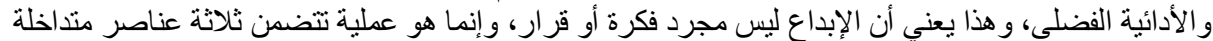

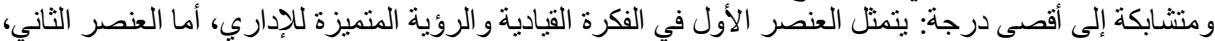

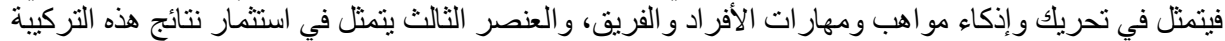

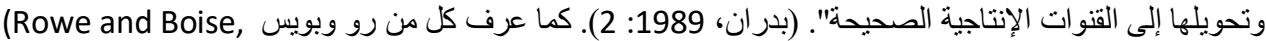

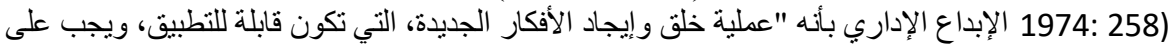

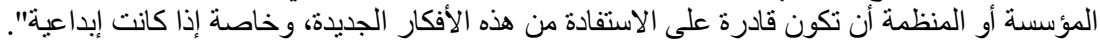

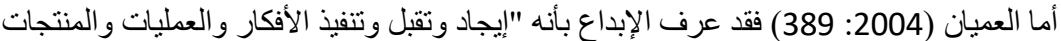

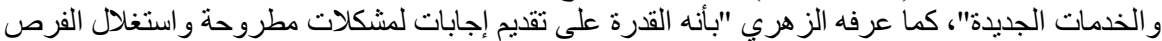

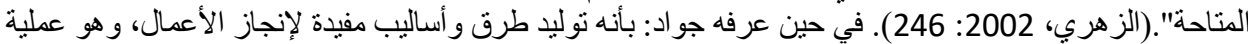

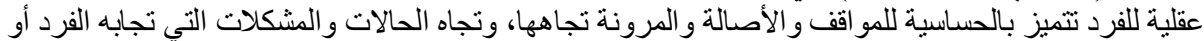

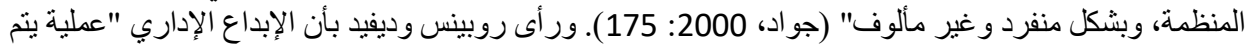

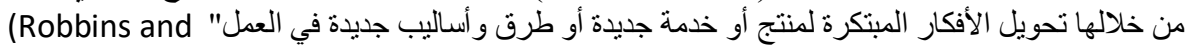

.David, 1998: 248)

أما الحو امده فقد عرف الإبداع الإداري "بأنه القدرة على إيجاد واستخدام أساليب ووسائل و أفكار ومهارات

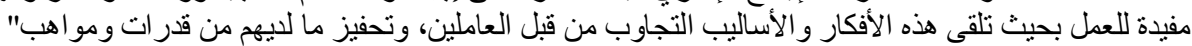

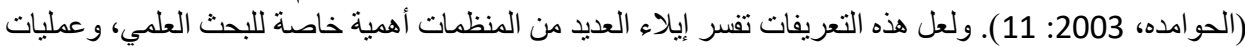

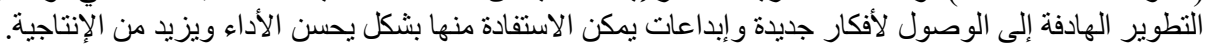

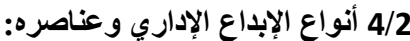

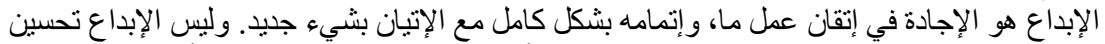

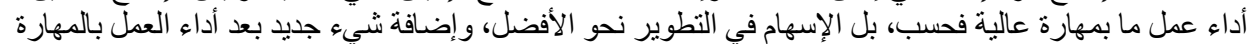

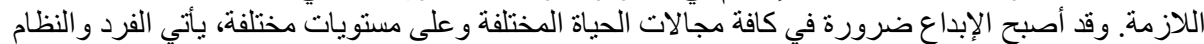

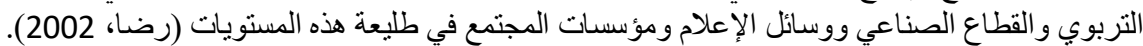

صنف إيفان (Evan, 1993) الإبداع إلى نو عين:

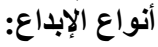

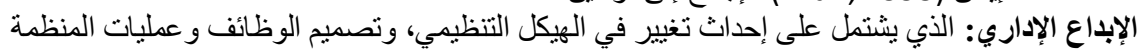
وسياساتها و إستر اتيجياتها ونظمها الإني الرقابية.

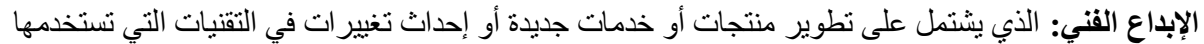

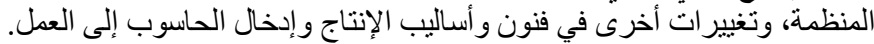

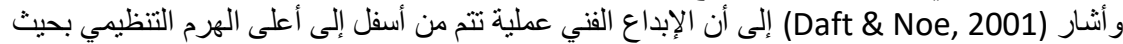

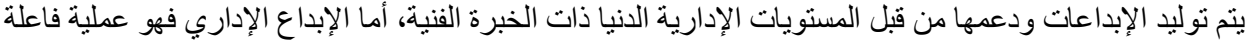

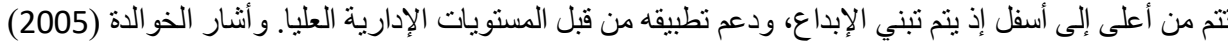

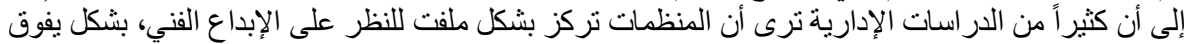

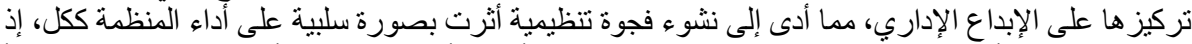

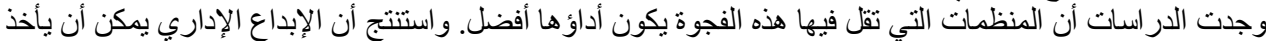

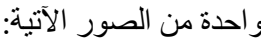

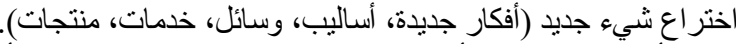

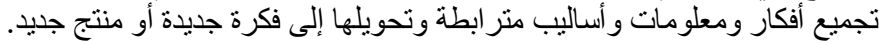

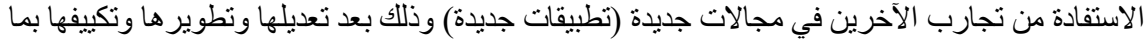

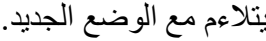

العمل على إحداث تغيير ات شكلية في المنتج و الخدمات لا تتجاوز المظهر العام له.

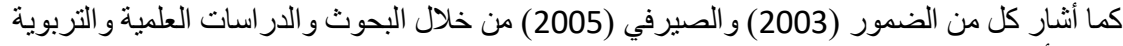

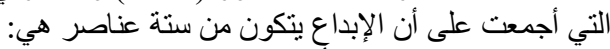

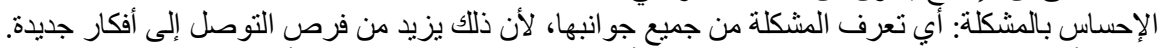

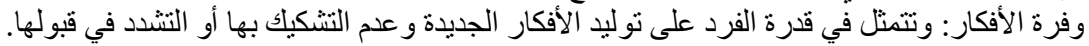


استجابات متنو عة تنتلاءم المرونة الموقفا هو النظر إلى الأشياء بمنظور جديد غير ما اعتاد عليه الناس، والقدرة على إعطاء

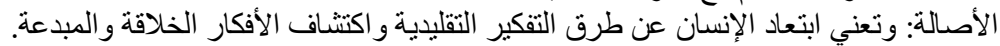

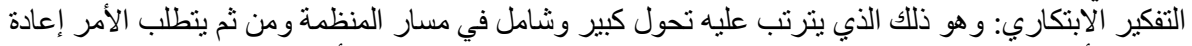

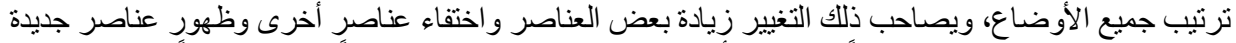

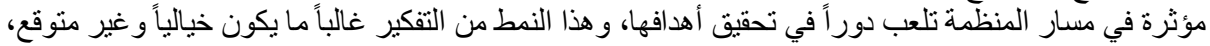

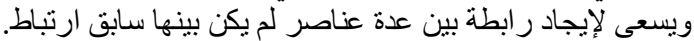

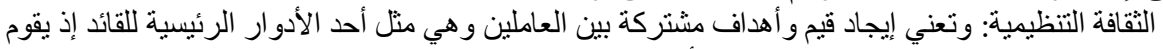

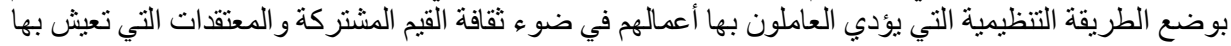
و أثنار المغربي (2004: 198) إلى أن هذه العناصر تشكل بمجمو عها سمات أساسية عامة يستدل بها على

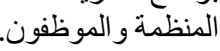

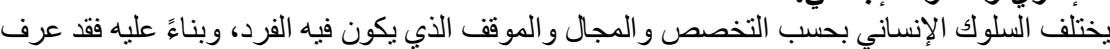

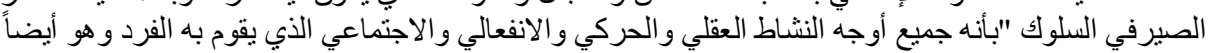

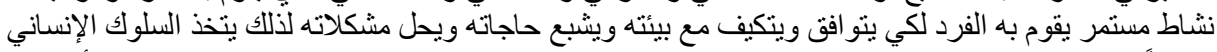

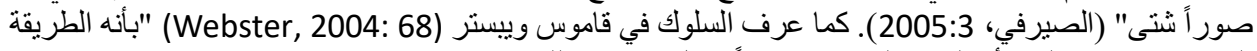

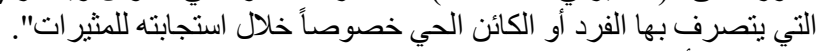

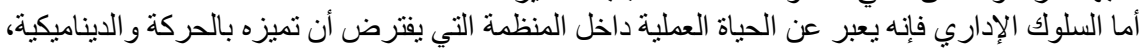

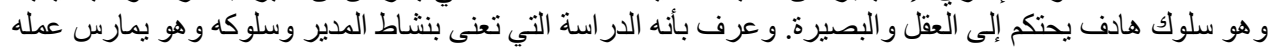

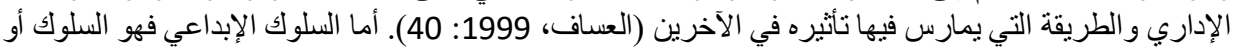

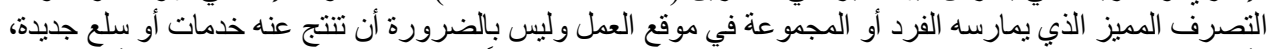

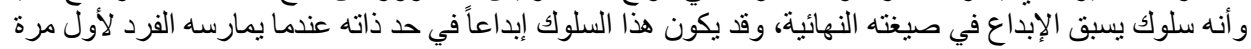

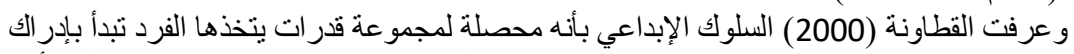

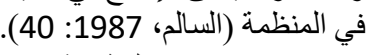

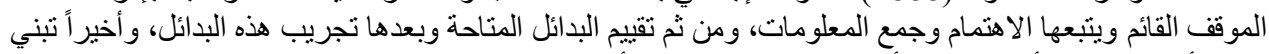

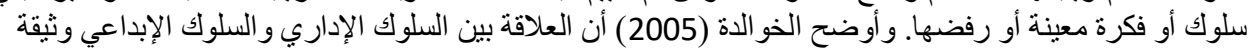

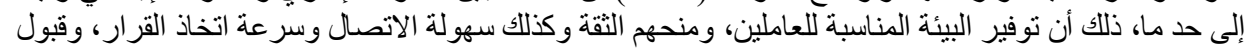

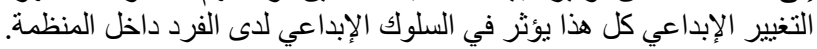

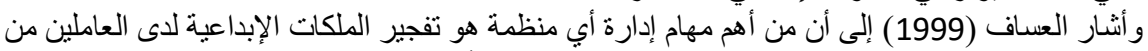

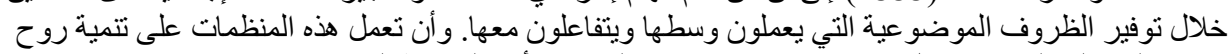

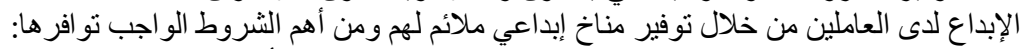

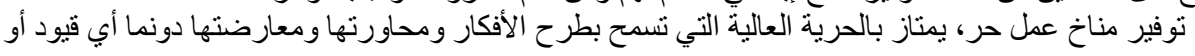

حدود.

قبادة الجماعة أو المنظمة، و أهم ما يشترط هنا، تميز هذه القيادة بالحافزيه التي تدفع كل فرد أن يكون مبدعاً:

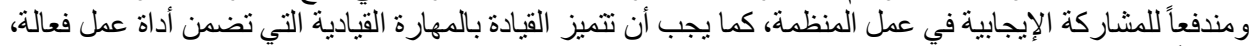

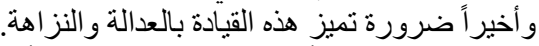

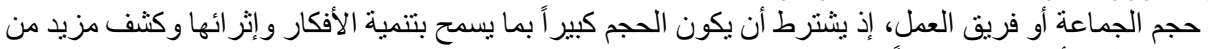

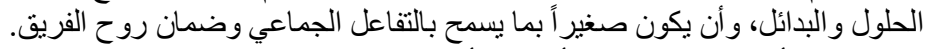

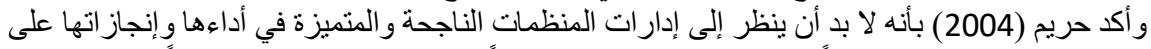

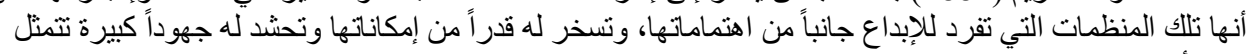


Reviewing the Concept of Innovation and it relationship with Organizational ...

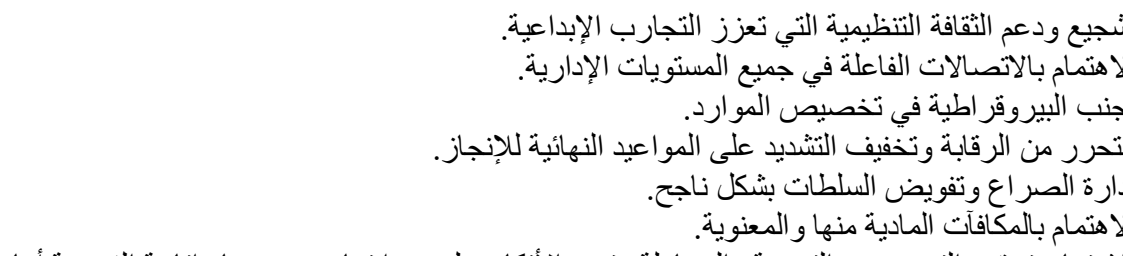

الاهتمام بتحقيق التوجه نحو التجربة والمحاولة وتبني الأفكار على غر ابتها وغموضها و إتاحة الفرصة أمام

الأفر اد لتجربتها.

الحد من العو ائق و التحديات التي تو اجه الإبداع وتذليلها.

6/2 المرتكزات الأساسية التي يقوم عليها الإبداع الإداري:

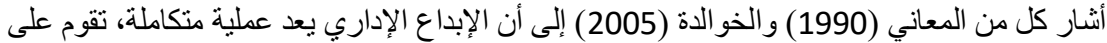

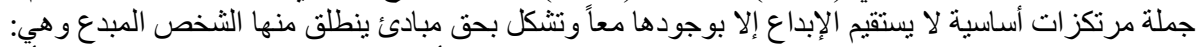

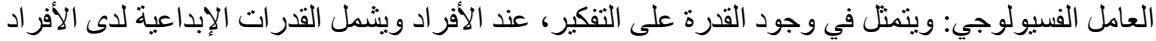

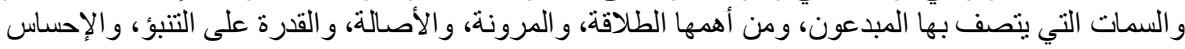

بالمشكلة، والقدرة على المثابرة وتحمل المخاطرة.

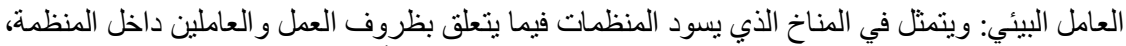

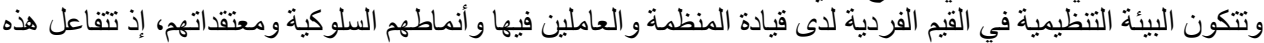

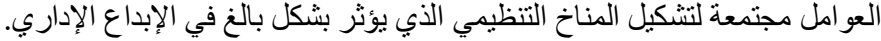

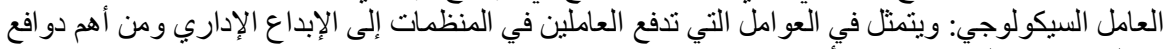

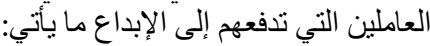

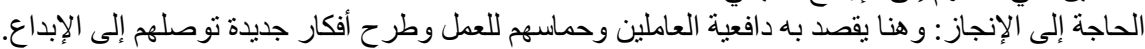

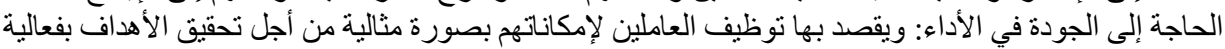
عالية. الحاجة إلى تحقيق الذات: وهي رغبة العاملين في إنجاز الأعمال التي تكون نابعة من داخلهم.

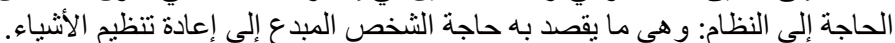

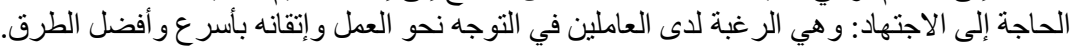

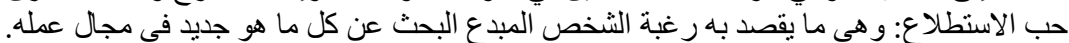

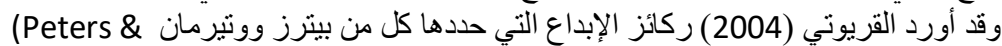

Waterman) التعريف بالقيم التنظيمية وتعميقها.

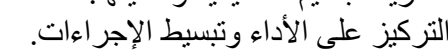
تشجيع روح الاستقلالية و المغامرة والإلبداع. معاملة العاملين بكر امة و إنسانية. خلق بيئة تنظيمية تتسم بالمرونة. 7/2 العل العملية الإبداعية:

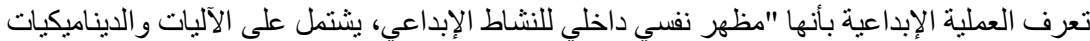

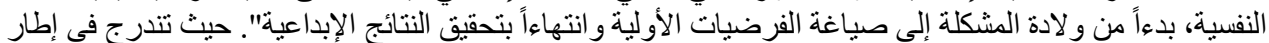

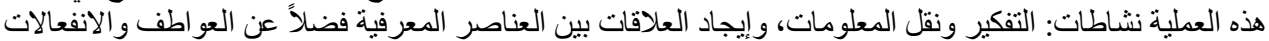

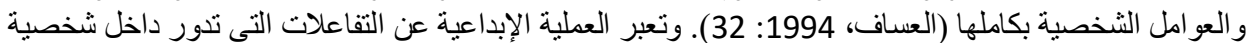

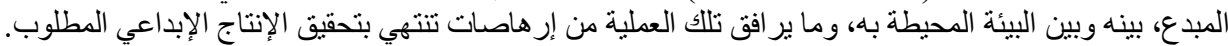

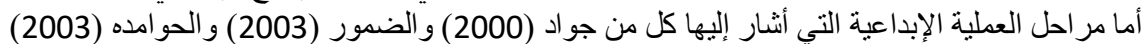

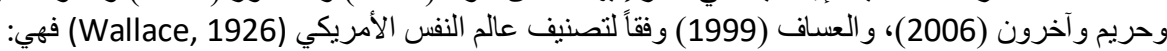
1.

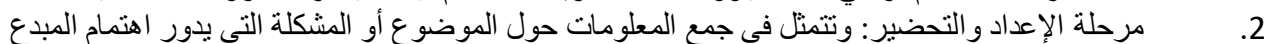

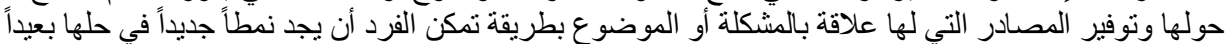

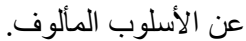

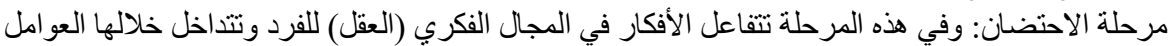

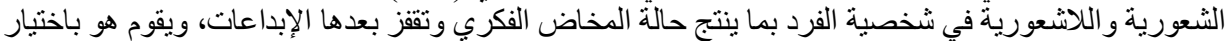




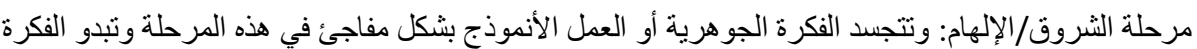

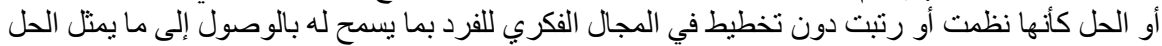
الأنموذجي.

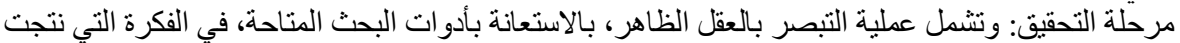

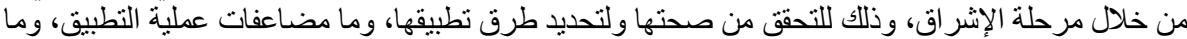

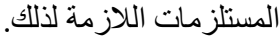

بينما أنشار الضمور (2003) إلى أن هناك أربع مر احل للإبداع (أو العمل الإبداعي) وردت في أنموذج

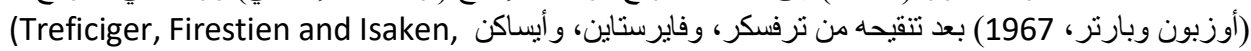

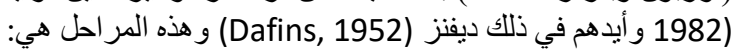
مرحلة اكتثافت الحقيقة: وتتضمن جمع كافة المعلومات حول المشكلة من خلال وضع أسئلة بصيغة، ماذا، أين، متى، كيف، لماذا؟ 2. مرحلة اكتثاف المشكلة: وتتضمن تحديد المشكلة وتعريفها بشكل واضح ودقيق.

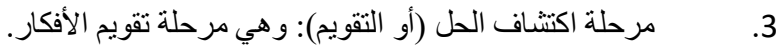

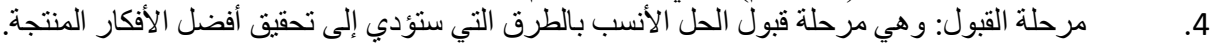

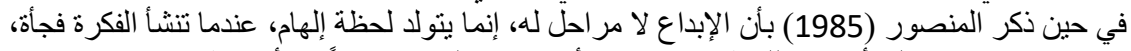

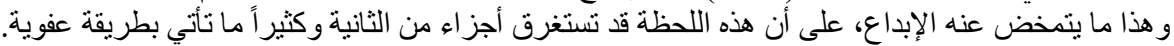

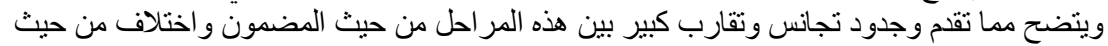

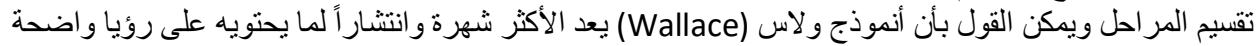

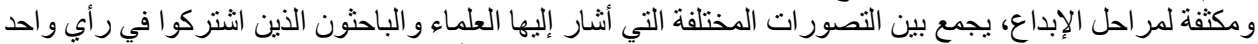

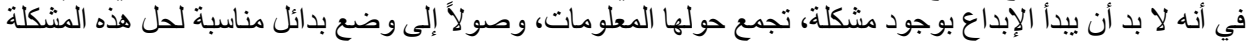
ثم اختيار الحل الأنسب وتطبيقه ومن هنا يتبين التقارب بين نماذج مر احل العملية الإبداعية من حيث المضمون مع الإنع اختلاف من حيث التفاصيل.

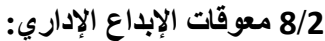

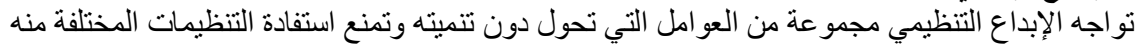

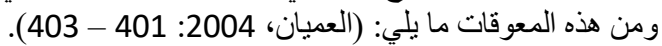

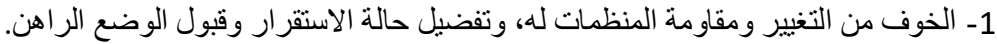

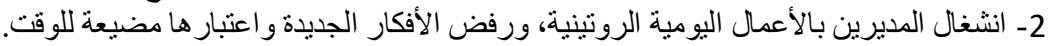

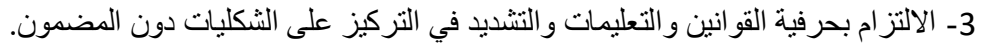

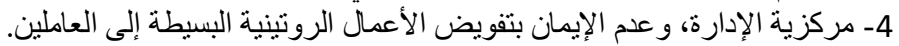

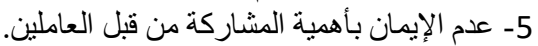

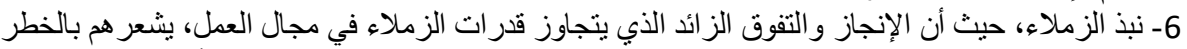

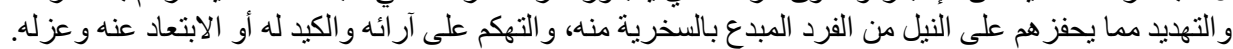

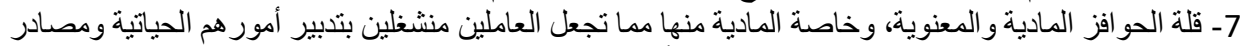

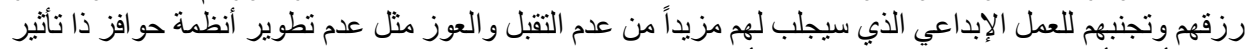

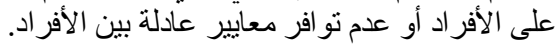

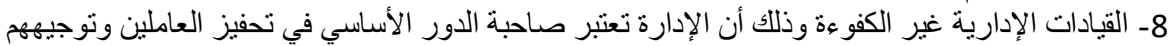

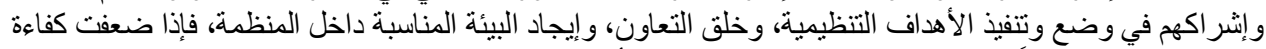

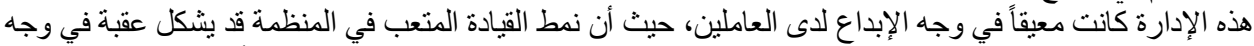

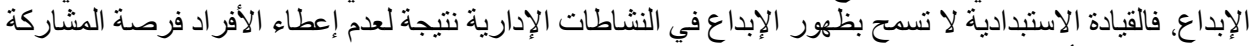

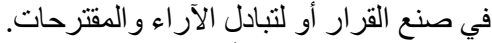

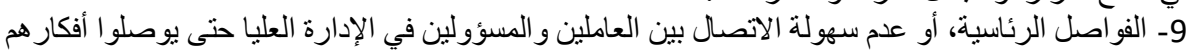
و وقتر حاتهم ويناقشونها معهم.

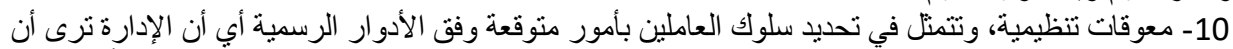

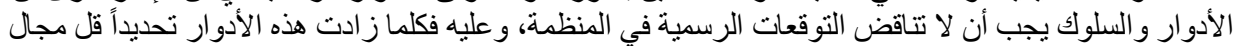

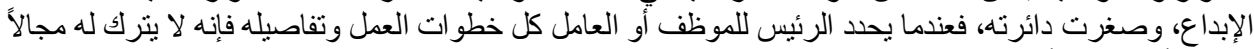
للإبداع أو طرح الأفكار الجديدة.

11- معوقات مالية للحيلولة دون بذل تكاليف محتملة كتكاليف تغيير الآلات أو تبديل الأنظمة الموجودة أو النماذج أو غير ذلك. 
Reviewing the Concept of Innovation and it relationship with Organizational ...

12- ضعف الو لاء التنظيمي، يؤدي ضعف و لاء و انتماء الفرد للمنظمة التي يعمل فيها إلى الاكتفاء بإنجاز الحد الأدنى

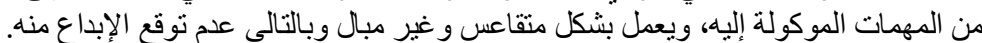

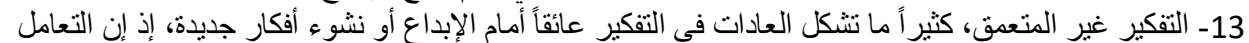

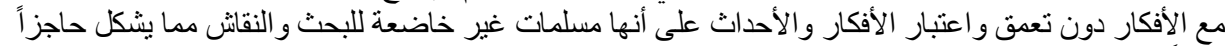

كما يمكن تصنيف القوى التي تقف عائقاً أمام الإبداع وتطوره على النحو التالي: (حريم، 2004: 40).

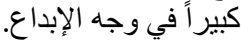

أـ المعوقات الثخصية أو الفردية وأهمها: المحاولة الدائمة لاستخدام المنطق والفية والبحث باستمر ار عن الجواب الصحيح.

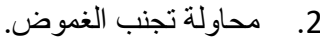

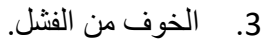
4. إهمال المشكلات التي تقع خار ج مجال الاختصاص. 5. 5. الخوف من تحمل المسؤولية. 6. اعتقاد الفرد أنه لبس مبلدعاً، و انخفاض إحساسه بأهميته. بـ معوقات من قبل المدير: وتتضمن ممارسات المدير السلبية التئية التي قد تنثل العمل الإبداعي و أهمها: 1

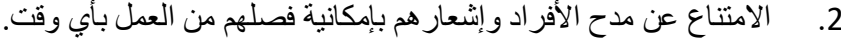

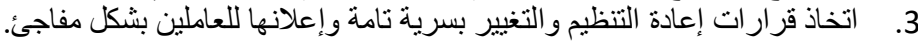

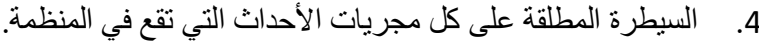

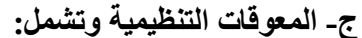
1 1 الالتز ام بحرفية القو انين والأنظمة. 2. 2. المناخ التنظيمي غير الصحي. الصني. 3 3. عدم وجود القيادات المؤهلة.

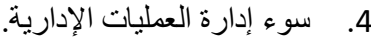

5. عدم توفر الموارد اللازمة و الإدية. 6. . تطبيق الهيكل التنظيمي غير السليج.

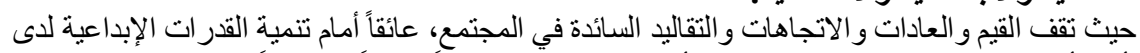

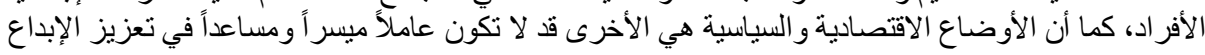
غير أن هنالك بعض العو امل الأخرى الهامة التي تعمل كمددات لمعدلات انتشار الابتكارات "الإبداعات" وتنميته. المتنو عة. (الحسن، 1999: 1991 141). 1- الميزة النسبية: حيث يتم الانتشار بدرجة أكبر عندما تكون الفكرة الجديدة أفضل بالمقارنة بالفكرة التي ستحل 2- التو افقت: فالانتشار يكون سهلاً عندما يكون منو افقاً مع القيم و المعتقدات و الحاجات و الممارسات الحالية للمتنبي

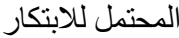

3- التعقيد: حيث أن الابتكارات صعبة الفهم تقل احتمالات انتشار ها.

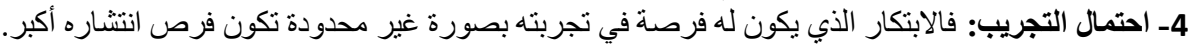

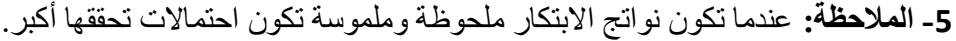

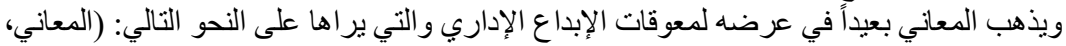


أما فيما يتعلق بالعو امل المؤثرة في الإبداع فهي لا تكاد تخرج عن واحدة من العو امل التالية كما ير اها:

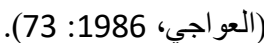

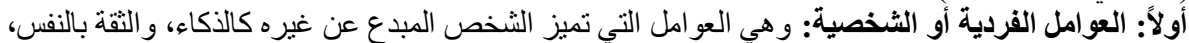

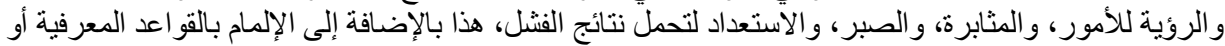

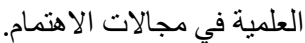

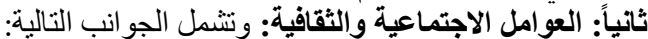

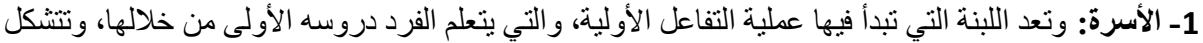

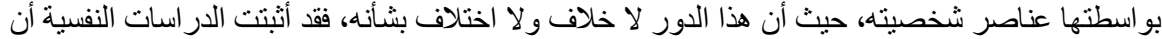

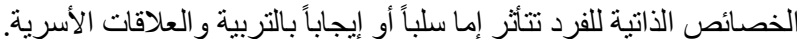

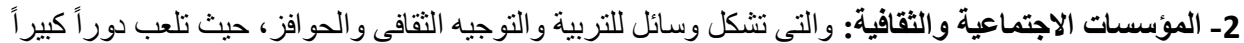

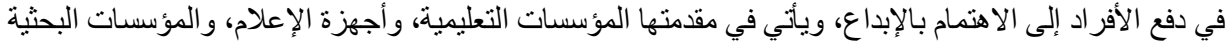
و الثقافية و المهنية.

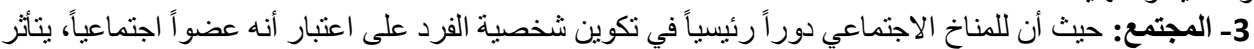

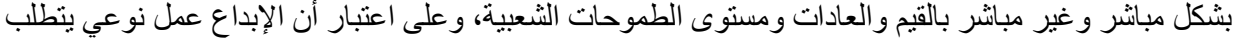

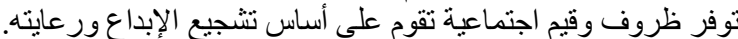

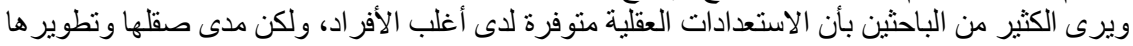

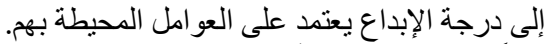

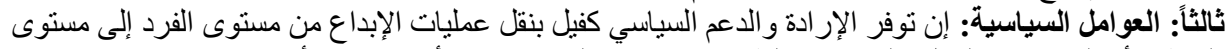

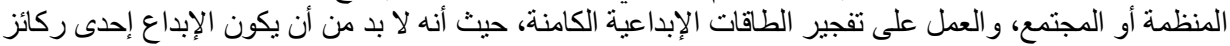

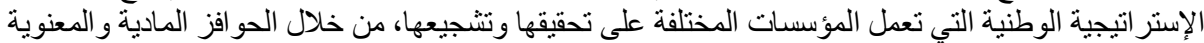

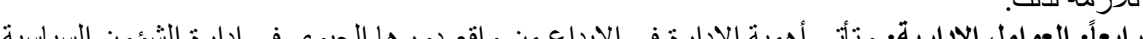

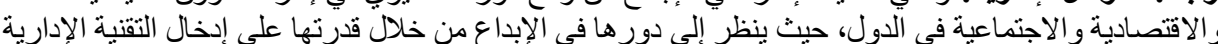

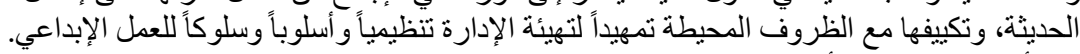

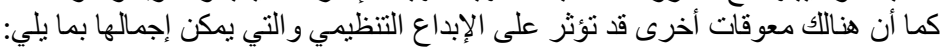
أولا: المعوقات الثخصية (الإدراكية):

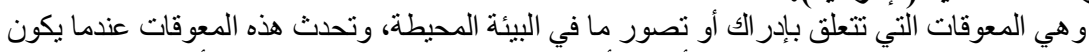

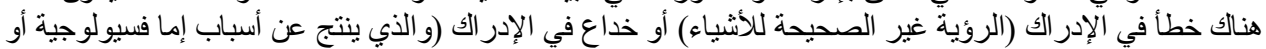

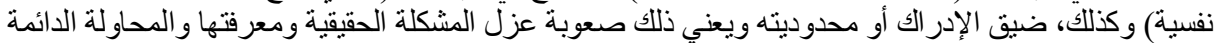

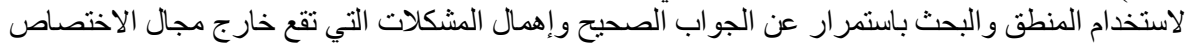

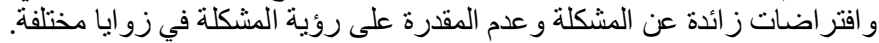
ثانيا: المعوقات النفسية والعاطفية:

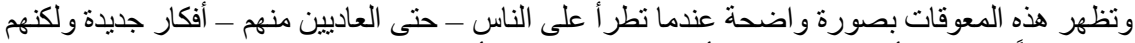

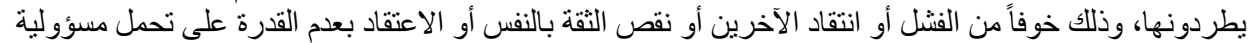

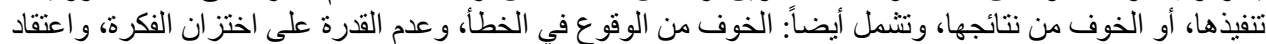

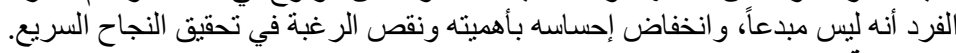

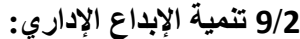

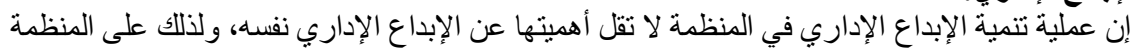

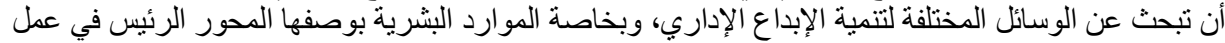

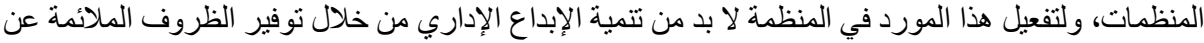
طريق تحسين وتطوير العمل في المنظمات.

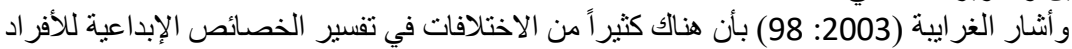

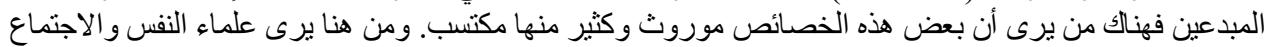

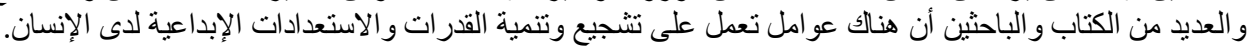

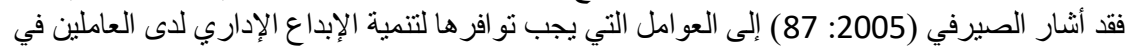

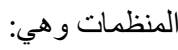

الإيمان بالاتنماء للمنظمة مما يدفع العاملين للمحافظة على ممتلكاتها وسمتها.

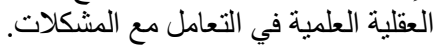
تحديد أهداف و اقعية للمشكلة. إيجاد مناخ وبيئة ملائمة لدعم التفكير الإبداعي للعاملين. 
Reviewing the Concept of Innovation and it relationship with Organizational ...

$$
\begin{aligned}
& \text { احتر ام الرأي و الرأي الآخر. }
\end{aligned}
$$

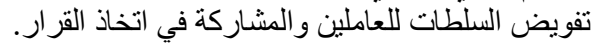

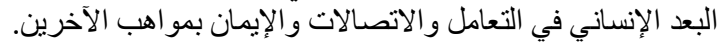

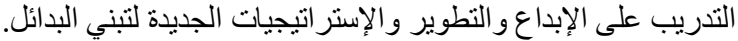

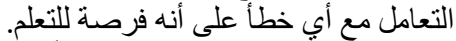

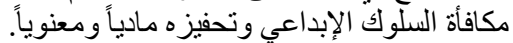

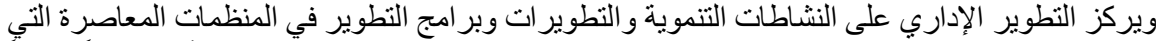

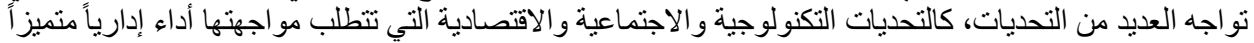
مبدعاً. فقد ذكرت عباس (2004: 77) بعض الأساليب التي تساعد هذه المنظمات في تطوير وتتمية الإبداع الإداري الإي التيات

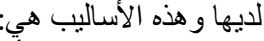

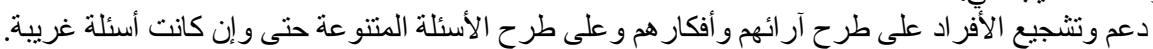

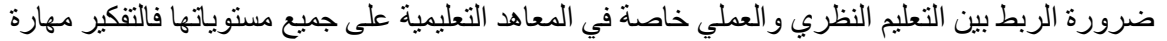

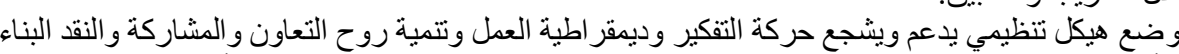
تنمو خلال التدريب و التطبيق.

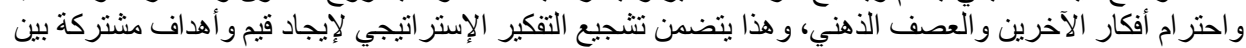
الاعنر اف بالفروف الفرين.

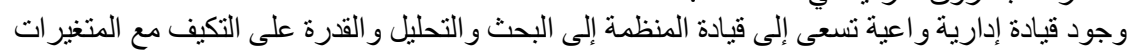
الاقتصادية و الاجتماعية و السياسية.

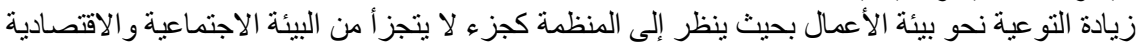

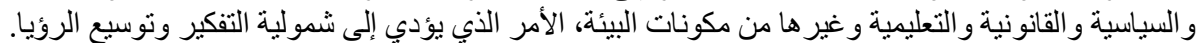
3 الدراسات السابقة:

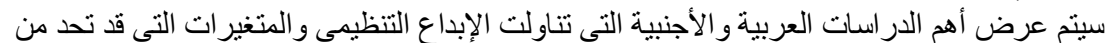

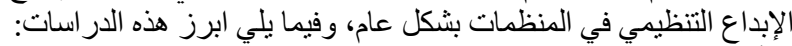

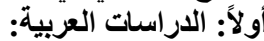

ـ در اسة الخو الدة (2005) بعنوان: " أثر استخدام تكنولوجيا المعلومات على الإبداع الإداري في

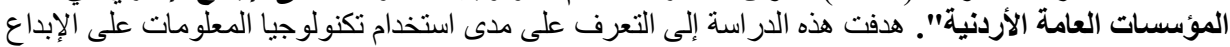

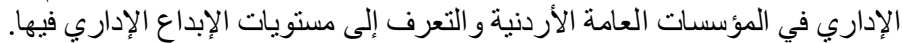

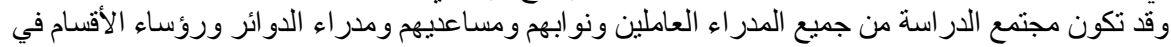
المؤسسات العامة المستقلة. ومن أبرز نتائج الأراسة:

وجود علاقة إيجابية وذات دولالة إلإنة إحصائية بين استخدام تكنولوجيا المعلومات والإبداع الإداري وبين طبيعة

وجود علاقة ذات دلالة إحصائية بين مدى ملائمة معلومات الإندات النظام المستخدم والإبداع الإداري وبين تكامل

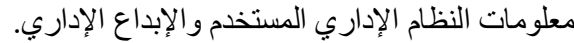
وجود علاقة ذات دلالة إحصائية بين إنتاجية نظام المعلومات الإدي، المستخدم والإبداع الإعاع الإداري.

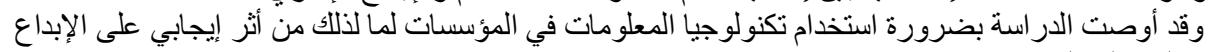

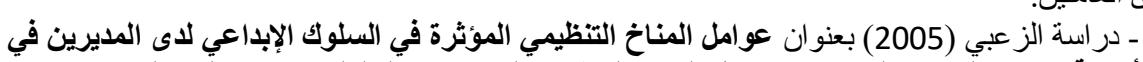
الإداري لدى العاملين.

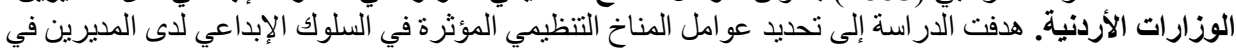
وقد تكون مجتمع الدر اسة من المديرين في الوزار ات الأردنية، أما عينة الدر اسة فتتكون من جميع المديرين الوزارات الأردنية.

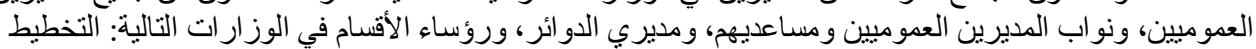

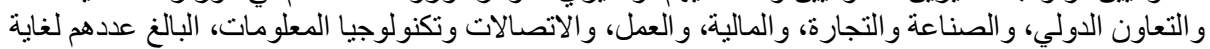
2004/12/1 (365) مديراً. وقد تم التوصل إلى عدد من النتائج أهمها :

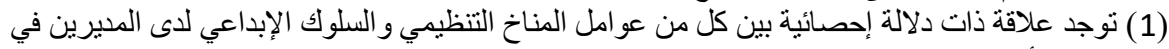

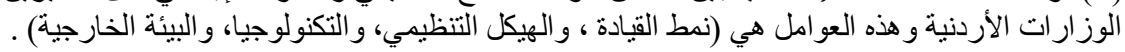

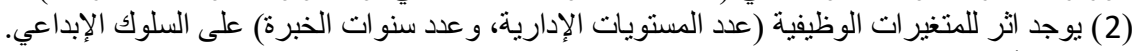
(3) هناك أثر للعمر على السلوك الإبداعي بينما لا يوجد اثر للجنس على السلوك الإبداعي كمتغير شخصي. 


$$
\begin{aligned}
& \text { وقد أوصت الدر اسة بضرورة إجر اء مزيد من الدراسات لتقصي أثر عوامل المناخ التنظيمي على السلوك }
\end{aligned}
$$

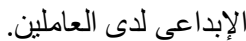

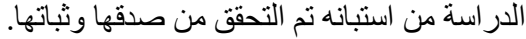

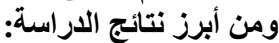

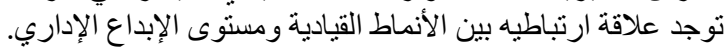

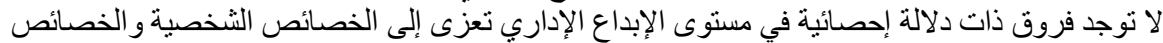

الثخصية للعاملين بالمديرية.

وقد أوصت الدراسة إلى ضرورة تفعيل نمط القيادة الديمقر اطي لما لذلك من أثر في تطوير المستوى

$$
\text { الإبداعي لاى العاملين في المؤسسات. }
$$

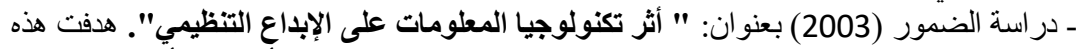

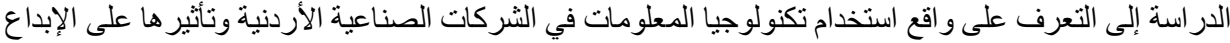

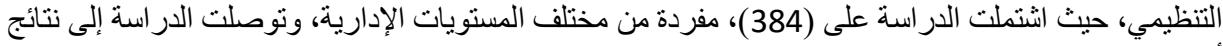

ـ وجود علاقة إيجابية بين تكنولوجيا المعلومات وتثجيع وتبني الإبداع كما توصلت الدر اسة إلى وجود علاقة إيجابية

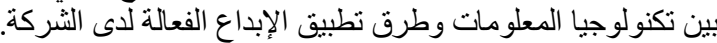

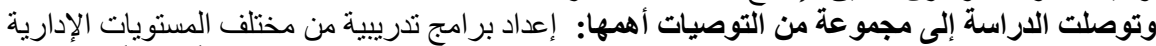

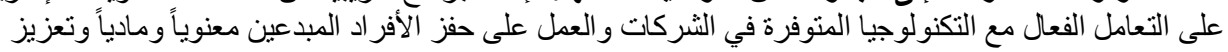

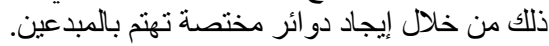

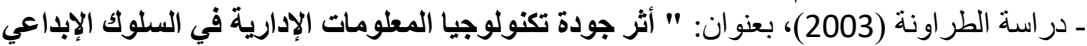

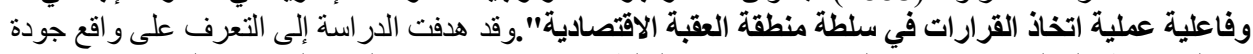

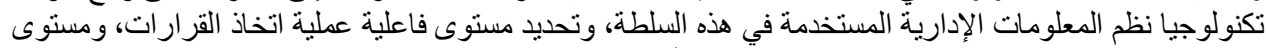

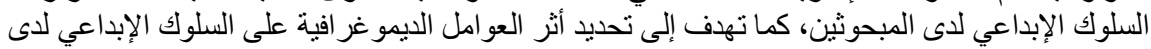

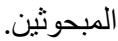

وقد تكون مجتمع الدر اسة من (250) موظفاً يعملون في سلطة منطقة العقبة، واستخدم الباحث استبانه لجمع المعلومات و الإجابة على فرضيات الدر استة.

\section{وتوصلت الاراسة إلى النتائج التالية:}

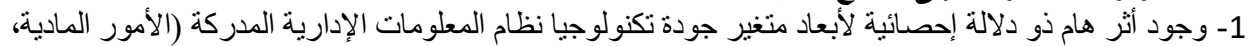

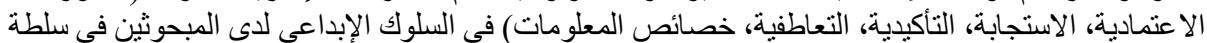
منطقة العقبة الاقتصادية الخاصة.

2- وجود أثر هام ذو دلالة إحصائية لأبعاد متغير جودة تكنولوجيا الإديا المعلومات الإدارية الددركة (الأمور المادية،

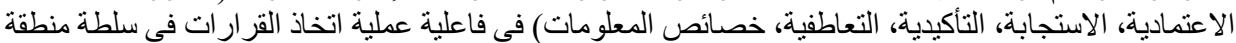

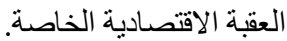
3- وجود فروقات ذات دلالة إحصائية بين تصور ات المبحوثين إز اء السلوك الإبداعي تعزى لمتغير ات (الجنس، العمر ، سنوات الخبرة، المؤهل العلى العيى).

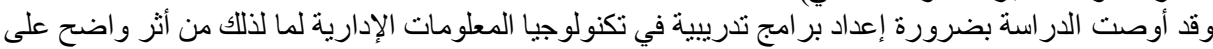

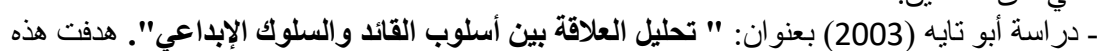
السلوك الإبداعي لدى الدأل العاملين.

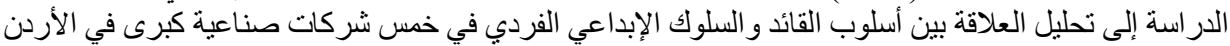

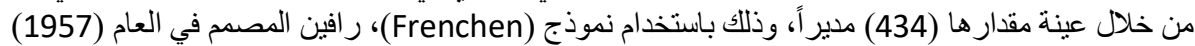
لمصادر قوة القائد، وكذلك نموذج السلوك الإبداعي الفردي المتعدد الأبعاد الذبي قدمه كلايسون وستريت في في العام

$$
\text { ون ومن أهم ما توصلت إليه الدراسة: }
$$

أن هنالك بعض مصادر قوة القائد لها أثر و اضح في تنجيع السلوك الإبداعي لدى العاملين مثل قوة سحر 
Reviewing the Concept of Innovation and it relationship with Organizational ...

أن هناك أنو اع أخرى من مصادر هذه القوة الثر عية وقوة المكافأة لم يتبين لها أثر واضح في التأثير في السلوك

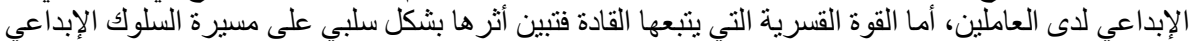

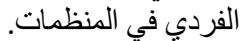

وقيد أوصت الدر اسة بضرورة إجر اء مزيد من الدر اسات للكثف عن أساليب القبادة الفعالة في تحقيق السلوك الإبداعي لدى العاملين.

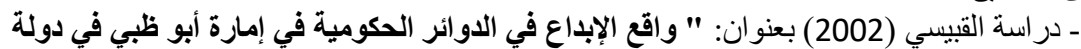

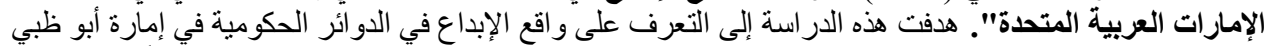

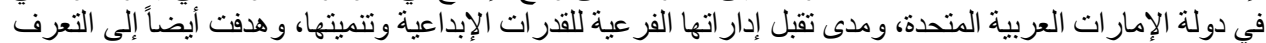

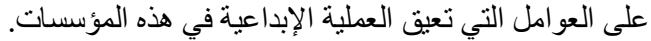

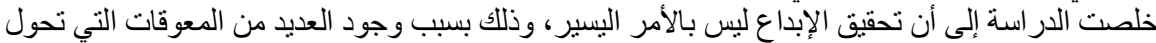

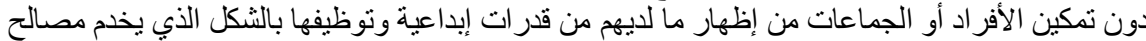

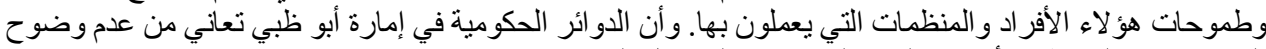

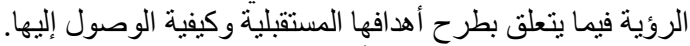

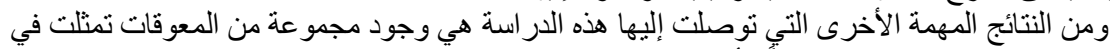

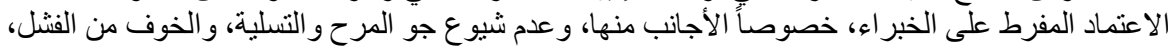

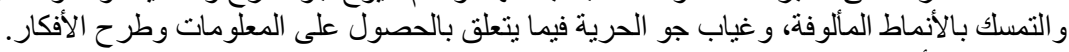

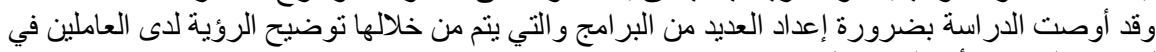

الدو ائر الحكومية ليقوموا بأعمالهم بشكل مناسب.

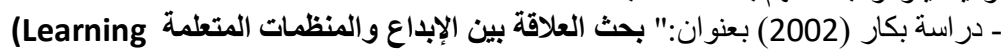

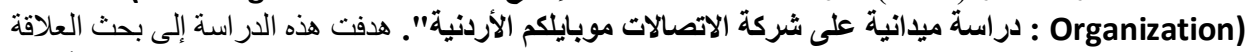

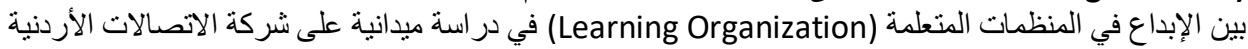

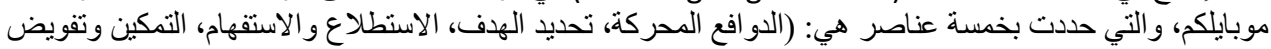
الصلاحيات، التقبيم و المر اجعة). وقد توصلت الدراسية:

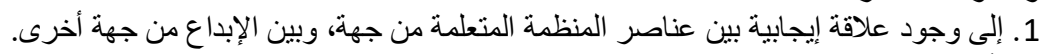

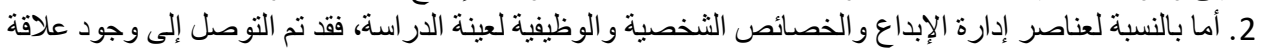

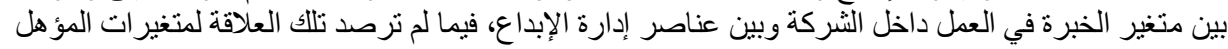

وقي أوصتث الدراسة بضرورة إعداد برامج تدرييية للعاملين في المنظمات، وذلك لتعريفهم بعناصر الإبداع العلمي و العمر.

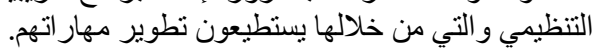

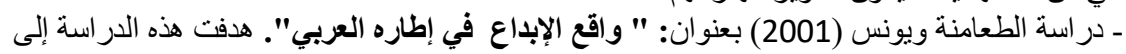

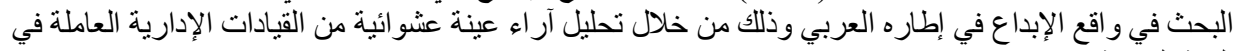

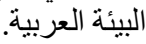
توصلت الار اسة إلى بعض النتائج أهمها:

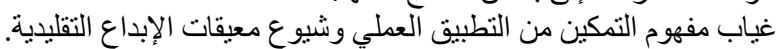

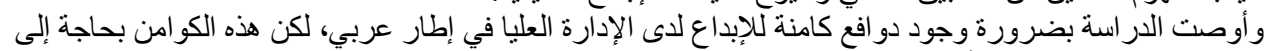

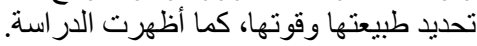

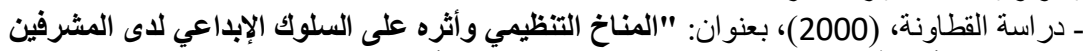

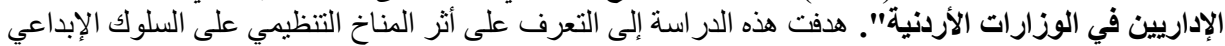

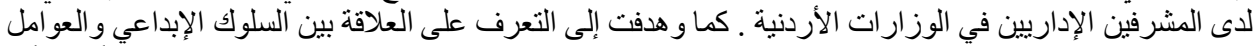
الديموغر افية (الجنس، العمر ، الوظيفة، المؤهل العلمي) للمشرفين الإداريين الذين بلغ لعنى عددهم (1128) مشرفاً إدارياً.

وقد توصلت الاراسة إلى عدة نتائج أهمها:

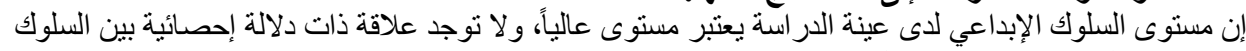

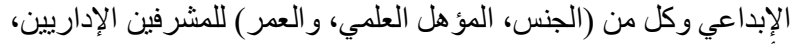

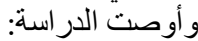

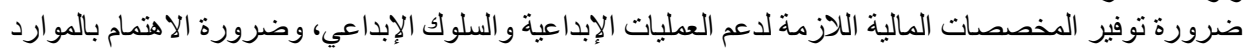

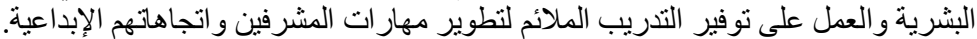

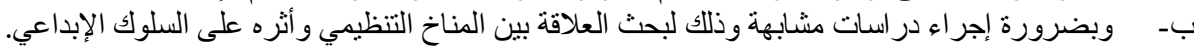


ـ دراسة الهيجان (1999) بعنوان : "معوقات الإبداع في المنظمات". هدفت هذه الدراعة الإعة بصورة أساسية

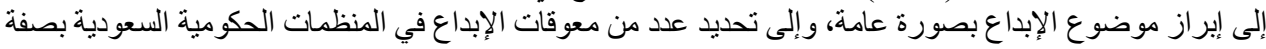

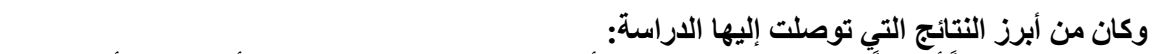

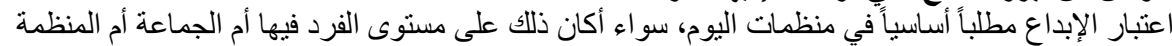

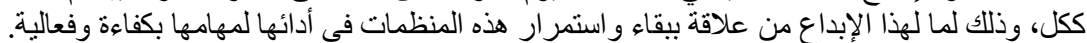

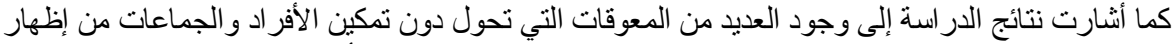

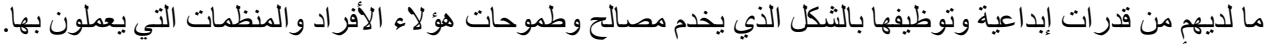

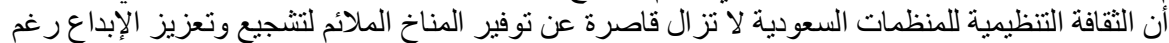

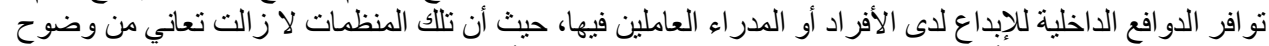

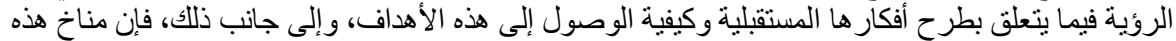

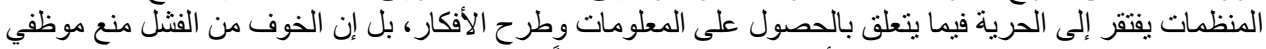

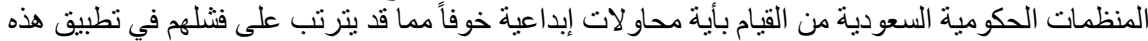

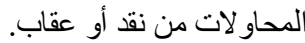

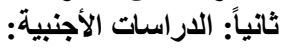

" The Influence of Creative Style and Climate on : بعنوان - دراسة (Fagan,2004)

Software Development Team Creativity: An Exploratory Study"

الاستكثافية إلى بحث تأثير أسلوب التفكير المتبع من قبل أفراد فرق العمل و المناخ السائد على الإبداع، وقد تكونت

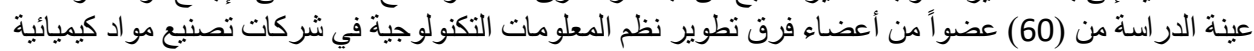

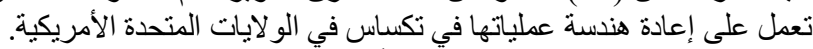

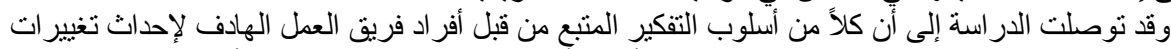

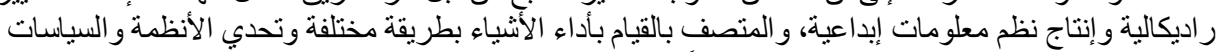

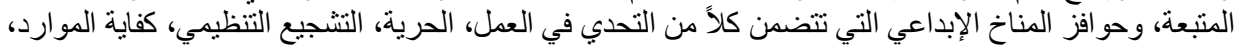

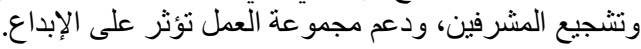

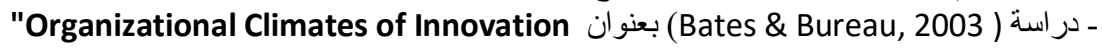
Across Federal Statistical Agencies"

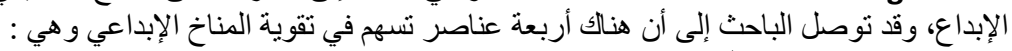
تقدير الإدارة للإبداع. تشجيع وتقوية الإبداع في أوقات ألفات الخطر. الانفتاح على طرق جديدة في ألداء ألماء المهام. أخذ آراء الموظفين بعين الاعتبار.

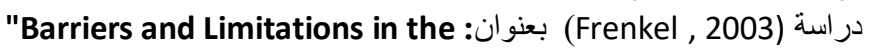

Development of Industrial Innovation in the Region"

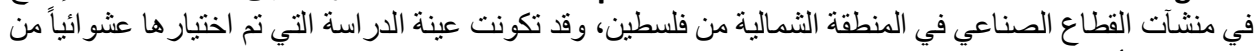

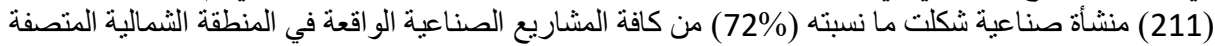

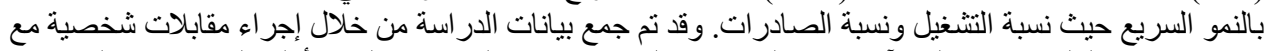

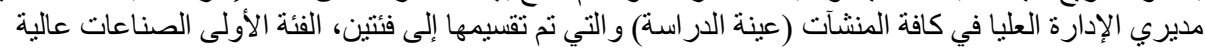

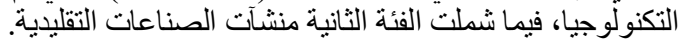

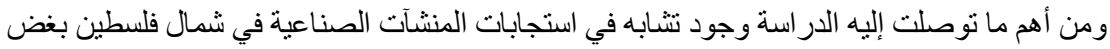

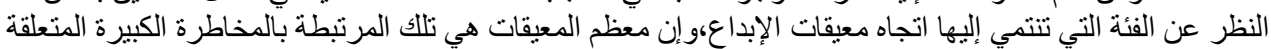

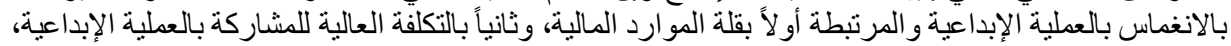

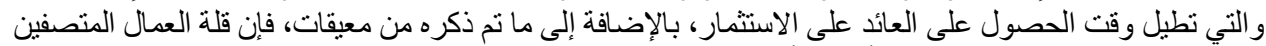

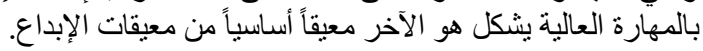

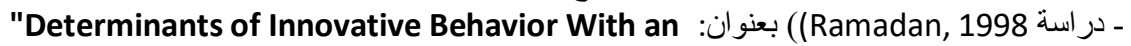

Application on Arab Academy for Science, Technology and Maritime Transport"

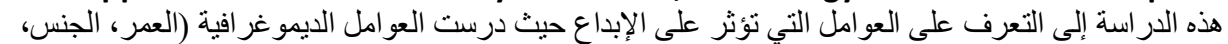

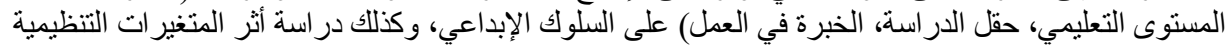
وشملت (السلوك القيادي، السلوك الإداري، نو عية مناخ العمل، تصميم العمل) على الإبداع. وقد توصلت هذه الدر اسة إلى: 
Reviewing the Concept of Innovation and it relationship with Organizational ...

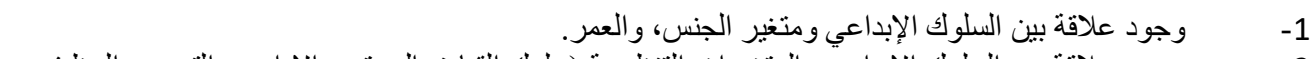

2- وجود علاقة بين السلوك الإبداعي و المتغير ات التنظيمية (سلوك القيادة، المستوى الإداري، التصميم الوظيفي،

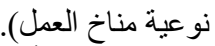

وقد أوصت الدر اسة بضرورة تحسين نوعية مناخ العمل من خلال دعم وتثجيع العاملين وتحليل

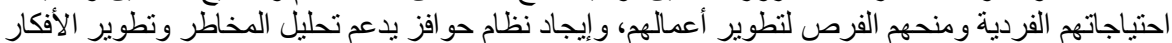

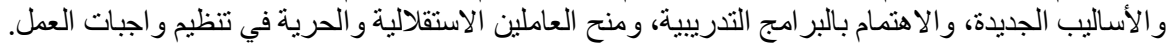

ـ در اسة (Robben , 1998) بعنوان:

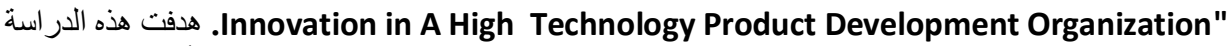

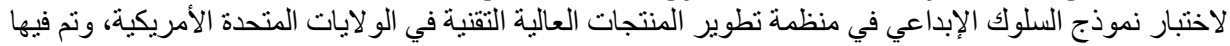

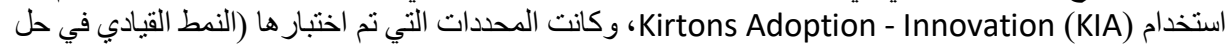

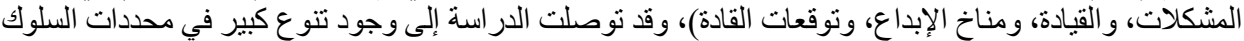
الإبداعي لدى مجمو عات الدر اسة.

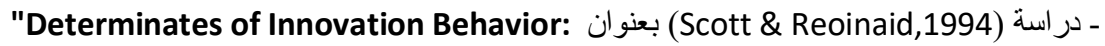

Path Model of Individual Innovation in the Work Place"

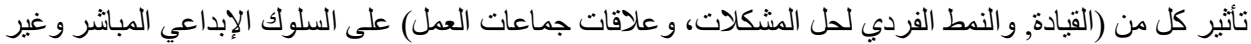

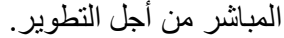
وخلصت الدراسة إلى نتائج أهمها:

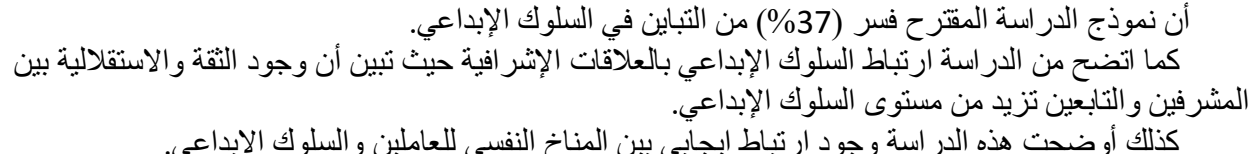

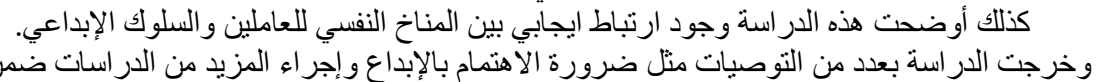

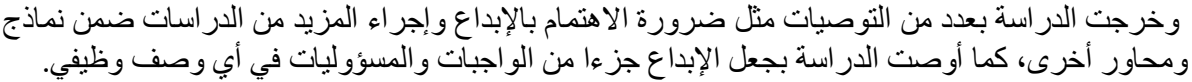

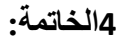

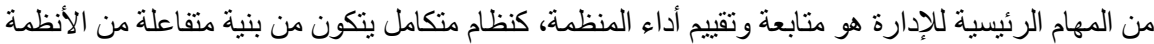

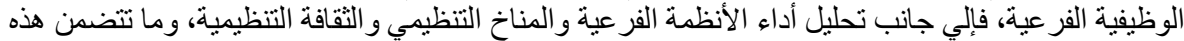

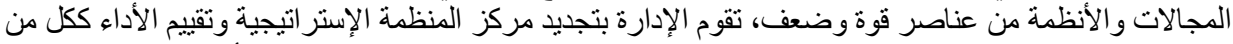

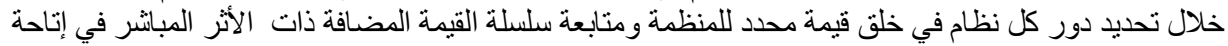

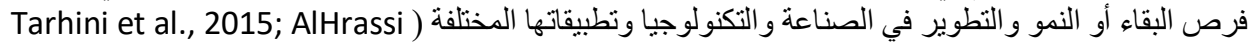

et al., 2016; Masa'deh et al., 2018a, b, c; Yassien \& Mufleh, 2017; Alenezi et al., 2017; Alkandari et al., 2017; Altamony \& Gharaibeh, 2017; Khwaldeh et al., 2017; Mikkawi \& AlLozi, 2017 (Lo وما آلت إليه التطور ات التكنولوجية في القرن الو احد و العشرين و الضغوطات التي تمخضت عن

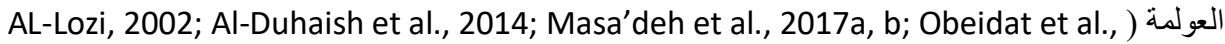
المعال

Khalayleh et al., 2017; Al-) اصبح يستخدم أساليب حديثة ومتطورة في مجال الإدارة و القرار الإداري AL-Syaidh et al., 2014, 2016; ) (dalahmeh et al., 2018 (Darawsheh et al., 2016; Masa'deh et al., 2015a, b

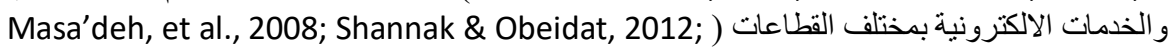
Karajeh \& Maqableh, 2014; Maqableh \& Karajeh, 2014; Al-Dmour et al., 2015; Almajali \& Maqableh, 2015; Maqableh \& Mohammed, 2015; Maqableh et al., 2015; Masa'deh, 2016; Tarhini et al., 2016, 2017a, 2017b; Almajali \& Al-Dmour, 2016; Almajali \& Tarhini,

2016; Almajali et al., 2016a, b; Aldmour et al., 2017; Obeidat et al., 2012, 2017, 2019; (Tarhini et al., 2018; Masa'deh, et al., 2019a, b; Al-Dmour et al., 2019

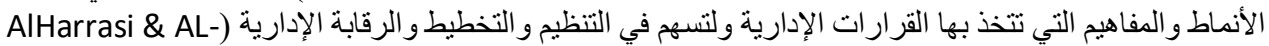

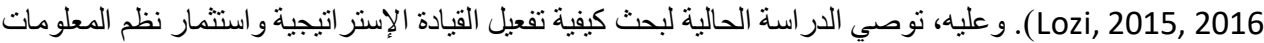
الإدارية المنطورة والحديثة من أجل تحقيق التميز المنظمي.

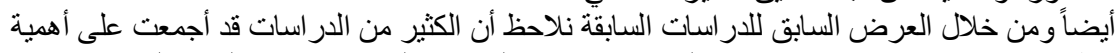

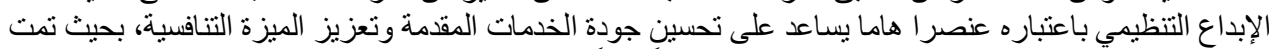

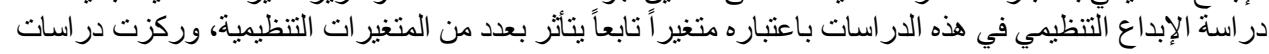




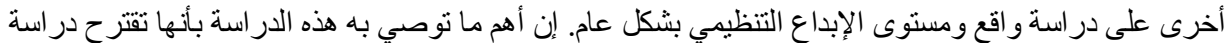

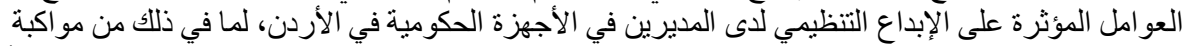

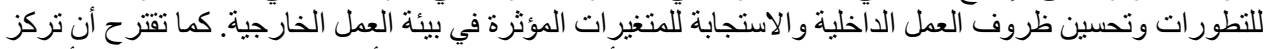

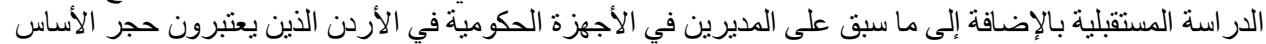

في التحول نحو استخدام هذه المفاهيم.

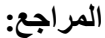

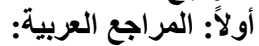

أبو تايه، سلطان نايف (2003)، العلاقة بين أسلوب القيادة و السلوك الإبداعي للفرد، دراسات، الجامعة الأردنية، مجلد (30)، عدد

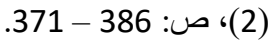

بدر ان، إبراهيم (2989)، ملاحظات حول الإبداع في الإدارة، عمان، الأردن: محاضر ات في تطوير الإدارة العليا المنعقد في

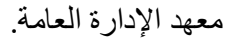

بكار، بر اءة (2002)، بحث العلاقة بين الإبداع و المنظمات المتعلمة (Learning Organization): در اسة ميدانية على شكل

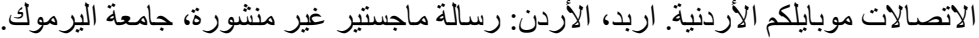

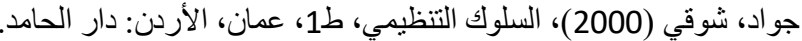

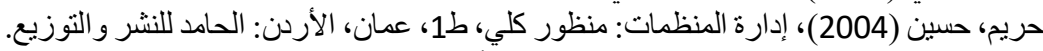

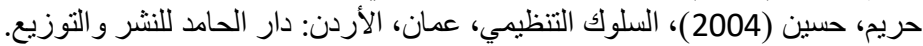

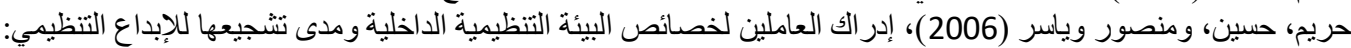

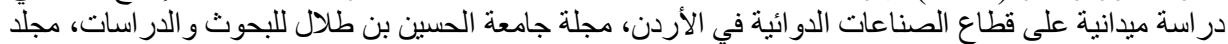

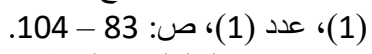

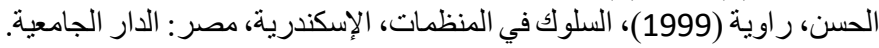

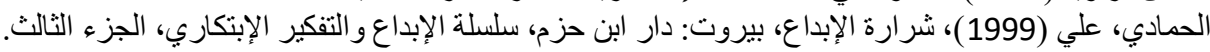

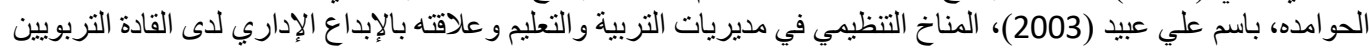

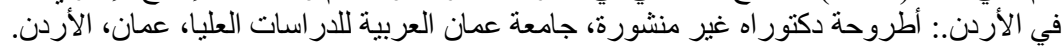

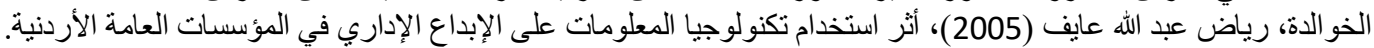
رسالة ماجستير غير منشورة، الجامعة الأردنية، عمان، الأردن.

الدهان، أميمة (1989)، الإبداع والسلوك الإبداعي للعاملين في المنظمة، مجلة تنمية الر افدين، المجلد الحادي عشر، العدد السادس

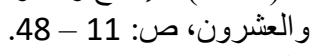

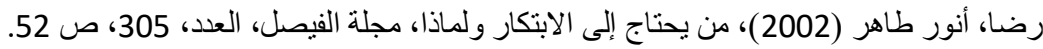

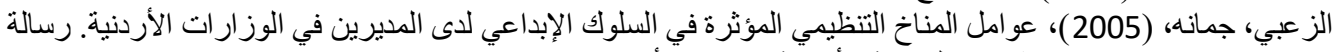

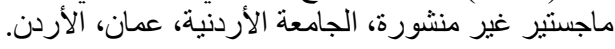

الزهري، رنده (2002)، الإبداع الإداري في ظل البيروقر اطية، الكويت، الكويت: عالم الفكر ، مجلد (30)، العدد (3)، ص 231.264

السالم، مؤيد، سعيد (1987)، المناخ التنظيمي، مفهوم حديث في الفكر الإداري المعاصر، المجلة العربية للإدارة، 1، (11)، 37-

الثقحاء، عادل (2004)، علاقة الأنماط القيادية بمستوى الإبداع الإداري، رسالة ماجستير غير منشورة، جامعة نايف العربية للعلوم الأمنية، الرياض، المملكة العربية.

الصيرفي، محمد عبد الفتاح (2005)، مفاهيم إدارية حديثة، (ط 1)، عمان، الأردن: الدارئ العار العلمية الجديدة للنشر و التوزيع.

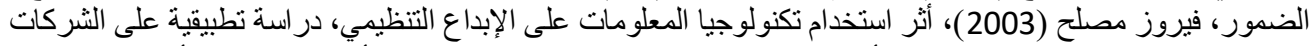

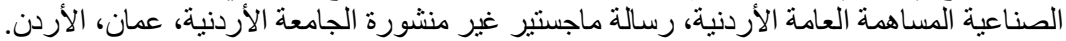

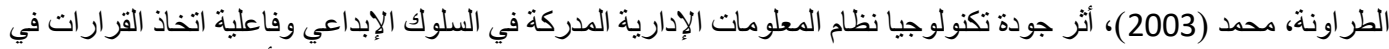

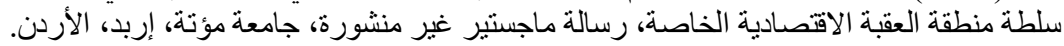

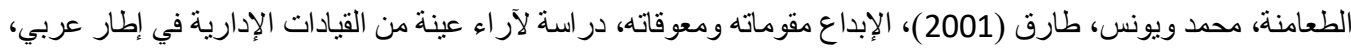

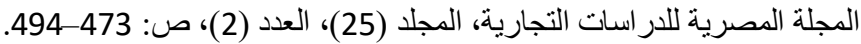

الطيب، حسن أبشر (1988)، فلسفة التطوير الإداري ودور القيادات الإدارية في تحقيق فعالينه، المجلة العربية للإدارة، المجلد

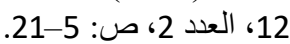

عباس، سهيله (12، (2004)، القيادة الابتكارية والأداء المتميز حقيبة تدريبية لتنمية الإبداع الإداري، (ط 1)، عمان، الأردن: دار و ائل

اللنشاف، حسين موسى (1999)، السلوك الإداري و التنظيمي في منظمات الأعمال، عمان، الأردن: دار زهران. 
Reviewing the Concept of Innovation and it relationship with Organizational ...

العساف، عبد المعطي محمد (2004)، (1994)، مقومات الإبداع الإداري في المنظمات المعاصرة، 17 (62)، 32.

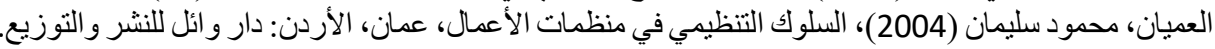

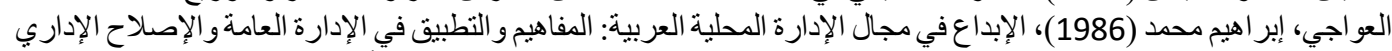

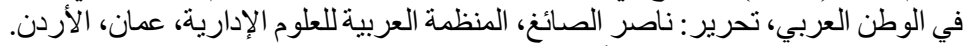

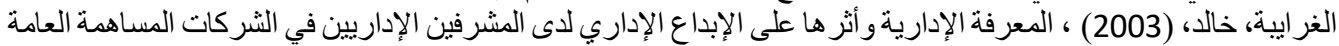

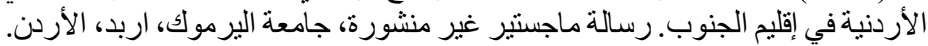

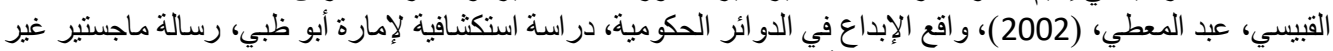
منشورة، جامعة اليرموك، إربد، الأردن. الإن.

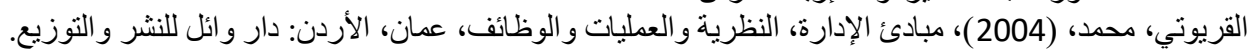

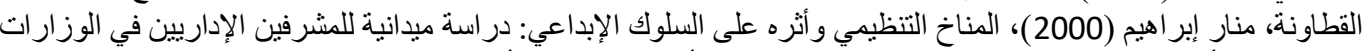

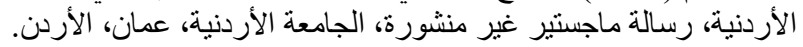

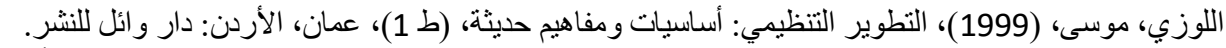

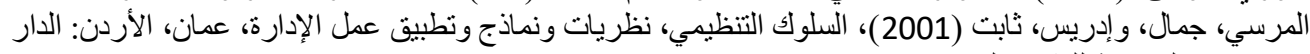

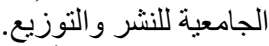
المعاني، أيمن عودة، (1990)، أثر الو لاء التنظيمي على الإبداع الإداري لدى المديرين في الوزار ات الأردنية، رسالة ماجستير غير

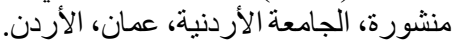

المغربي، كامل محمد (2004)، السلوك التنظيمي، مفاهيم وأسس سلوك الفاردي، الفرد و الجماعة في التنظيم، (ط 3)، عمان، الأردن: دار الفكر.

المنصور ، زهير، (1985)، مقدمة في منهج الإبداع. الكويت: دار ذات السلاسل للطباعة و النشر.

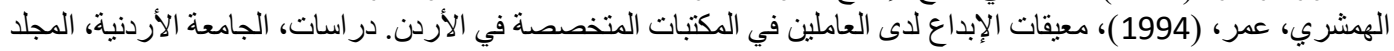

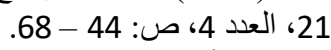

الهيجان، عبد الرحمن أحمد محمد، (1999)، معوقات الإبداع في المنظمات، الإدارة العامة، المجلد (39)، العدد (1)، ص: 1.77

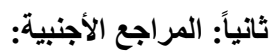

\section{References}

Abualoush, S., Bataineh, K., \& Alrowwad, A. (2018a). The Role of Knowledge Management Process and Intellectual Capital as Intermediary Variables between Knowledge Management Infrastructure and Organization Performance. Interdisciplinary Journal of Information, Knowledge, and Management, 13, 279-309.

Abualoush, S., Obeidat, B., \& Tarhini, A. (2018b). The Role of Employees' Empowerment as an Intermediary Variable between Knowledge Management and Information Systems on Employees' Performance. VINE Journal of Information and Knowledge Management Systems, 48(2), 217-237.

Adair, J. (1985). Management Decision Making. Grower Publishing.

Alananzeh, O., Jawabreh, O., Al-Mahmoud, A., \& Hamada, R. (2018). The Impact of Customer Relationship Management on Tourist Satisfaction: The Case of Radisson Blue Resort in Aqaba City. Journal of Environmental Management and Tourism, 2(26), 227240.

Al-dalahmeh, M., Khalaf, R., \& Obeidat, B. (2018). The Effect of Employee Engagement on Organizational Performance via the Mediating Role of Job Satisfaction: The Case of IT Employees in Jordanian Banking Sector. Modern Applied Science, 12(6), 17-43. 
Al-Dmour, R., Al Haj Dawood, E., Al-Dmour, H., \& Masa'deh, R. (2019). The Effect of Customer Lifestyle Patterns on the Use of Mobile Banking Applications in Jordan. Int. J. Electronic Marketing and Retailing, Forthcoming.

Aldmour, R., Masa'deh, R., \& Obeidat, B. (2017). Factors Influencing the Adoption and Implementation of HRIS Applications: Are they Similar. International Journal of Business Innovation and Research, 14(2), 139-167.

Al-Dmour, R, Obeidat, B., \& Almajali, D. (2015). The Practice of HRIS Applications in Business Organizations in Jordan: An Empirical Study. 4th Scientific \& Research Conference on New Trends in Business, Management and Social Sciences (COES\&RJTK15/1).

Al-Duhaish, A., Alshurideh, M., \& Al-Zu'bi, Z. (2014). The Impact of the Basic Reference Group Usage on the Purchasing Decision of Clothes (A Field Study of Saudi Youth in Riyadh City). Dirasat: Administrative, 41(2), 205-221.

Alenezi, H., Tarhini, A., Alalwan, A., \& Al-Qirim, N. (2017). Factors Affecting the Adoption of E-Government in Kuwait: A Qualitative Study. Electronic Journal of e-Government, 15(2), 84-102.

AlHarrasi, J., \& AL-Lozi, M. (2015). The Role of Innovation Management and Technological Innovation on Organizational Effectiveness. 4th Scientific \& Research Conference on New Trends in Business, Management and Social Sciences (COES\&RJTK15/1), Istanbul, Turkey.

AlHarrasi, J., \& AL-Lozi, M. (2016). The Role of Innovation Management and Technological Innovation on Organizational Effectiveness: A Theoretical Model. Journal of Social Sciences (COES\&RJ-JSS), 5(1), 80-95.

AlHrassi, J., Al-Lozi, M., \& Irtaimeh, H. (2016). The Impact of Management Innovation and Technological Innovation on Organizational Effectiveness: An Empirical Study from Managerial Staff Perspective in Sultan Qaboos University. Journal of Social Sciences (COES\&RJ-JSS), 5(3), 309-339.

Alkandari, A., Masa'deh, R., \& Al-Lozi, M. (2017). Knowledge Management and its Role on Organizational Crisis Management: A Literature Review. Journal of Social Sciences (COES\&RJ-JSS), 6(4), 833-850.

AL-Lozi, M. (2002). Total Quality Management in the Civil Service Institutions in Jordan. Mu'tah: Humanities and Social Sciences Series, 18(4), 151-185.

Almajali, D., \& Al-Dmour, R. (2016). The Role of Information Technology in Motivating Students to Accept E-Learning Adoption in Universities: A Case Study in Jordanian Universities. Journal of Business \& Management (COES\&RJ-JBM), 4(1), 36-46. 
Almajali, D., \& Maqableh, M. (2015). Assessing the Digital Divide Status of the Jordanian Telecentre. International Journal of Communications, Network and System Sciences, 8(11), 428-439.

Almajali, D., \& Tarhini, A. (2016). Antecedents of ERP Systems Implementation Success: A Study on Jordanian Healthcare Sector. Journal of Enterprise Information Management, 29(4), 549-565.

Almajali, D., Mansour, K., \& Maqableh, M. (2016a). The Impact of Electronic Supply Chain Management Usage on Firm's Performance. International Journal of Communications, Network and System Sciences, 9(6), 280-293.

Almajali, D., Masa'deh, R., \& Al-Lozi, M. (2016b). Determinants of the Actual Use of ELearning Systems: An Empirical Study on Zarqa University in Jordan. Journal of Social Sciences (COES\&RJ-JSS), 5(2), 172-200.

AL-Syaidh, N., Al- Lozi, M., \& AlHarrasi, J. (2016). Transformational Leadership and its Role on the Effectiveness of Employees' Behavior: A Theoretical Study. Journal of Business \& Management (COES\&RJ-JBM), 4(1), 14-35.

AL-Syaidh, N., Masa'deh, R., \& Al-Zu'bi, Z. (2014). Transformational Leadership and its Impact on the Effectiveness of Employees' Behavior in the Public and Private Jordanian Hospitals. Jordan Journal of Business Administration, 11(1), 23-57.

Altamony, H., \& Gharaibeh, A. (2017). The Role of Academic Researcher to Mintzberg's Managerial Roles. International Journal of Business Management and Economic Research, 8(2), 920-925.

Bates, N., \& Bureau, C. (2003). Organizational Climates of Innovation across Federal Statistical Agencies, Census Bureau Staff, Washington D.C.

Daft, R., \& Noe, R. (2001). Organizational Behavior. Bandon Organization: Southwestern Publishing.

Darawsheh, S., ALshaar, A., \& AL-Lozi, M. (2016). The Degree of Heads of Departments at the University of Dammam to Practice Transformational Leadership style from the Point of View of the Faculty Members. Journal of Social Sciences (COES\&RJ-JSS), 5(1), 56-79.

Evan, W. (1993). Organization Theory. New York. Macmillan Publishing Co.

Fagan, H. (2004). The Influence of Creative Style and climate on Software Development team creativity: An Exploratory Study. Journal of Computer Information Systems, Spring, 73-80.

Frenkel, A. (2003). Barriers and Limitations in the Development of Industrial Innovation in the Region. European Planning Studies, 11(2), 115-137. 
Gray, J., \& Strake, F. (1988). Organizational Behavior: Concepts and Applications. (4 ${ }^{\text {th }}$ ed.)., Ohio Columbus: Merrill Publishing Company.

Karajeh, H., \& Maqableh, M. (2014). Security of Cloud Computing Environment. The 23rd IBIMA Conference on Vision 2020: Sustainable Growth, Economic Development, and Global Competitiveness, USA, 2202-2215.

Khalayleh, W., Masa'deh, R., \& Al-Lozi, M. (2017). Administrative Empowerment and its Role on the Work Teams Performance: A Literature Review. Journal of Social Sciences (COES\&RJ-JSS), 6(4), 851-868.

Khwaldeh, S., Al-Hadid, I., Masa'deh, R., \& Alrowwad, A. (2017). The Association between E-Services Web Portals Information Quality and ICT Competence in the Jordanian Universities. Asian Social Science, 13(3), 156-169.

Maqableh, M., \& Mohammed, A. (2015). The Acceptance and Use of Computer based Assessment in Higher Education. Journal of Software Engineering and Applications, 8(10), 557.

Maqableh, M., \& Karajeh, H. (2014). Job Scheduling for Cloud Computing using Neural Networks. Communications and Network, 6(3), 191-200.

Maqableh, M., Rajab, L., Quteshat, W., Khatib, T., \& Karajeh, H. (2015). The Impact of Social Media Networks Websites Usage on Students' Academic Performance. Communications and Network, 7(4), 159-171.

Masa'deh, R. (2016). The Role of Knowledge Management Infrastructure in Enhancing Job Satisfaction at Aqaba Five Star Hotels in Jordan. Communications and Network, 8(4), 219-240.

Masa'deh, R., Alananzeh, O., Algiatheen, N., Ryati, R., Albayyari, R., \& Tarhini, A. (2017a). Employee's Perception of Implementing Green Supply Chain Management on Hotel's Economic and Operational Performance. Journal of Hospitality and Tourism Technology, 8(3), 395-416.

Masa'deh, R., Shannak, R., Maqableh, M., \& Tarhini, A. (2017b). The Impact of Knowledge Management on Job Performance in Higher Education: The Case of the University of Jordan. Journal of Enterprise Information Management, 30(2), 244-262.

Masa'deh, R., Alananzeh, O., Algudah, O., \& Tarhini, A. (2018a). The Effect of Promotional Mix on Hotel Performance during the Political Crisis in the Middle East. Journal of Hospitality and Tourism Technology, 9(1), 33-49.

Masa'deh, R., Alrowwad, A., Alkhalafat, F., Obeidat, B., \& Abualoush, S. (2018b). The Role of Corporate Social Responsibility in Enhancing Firm Performance from the Perspective of IT Employees in Jordanian Banking Sector: The Mediating Effect of Transformational Leadership. Modern Applied Science, 12(7), 1-26. 
Reviewing the Concept of Innovation and it relationship with Organizational ...

Masa'deh, R., Al-Henzab, J., Tarhini, A., \& Obeidat, B. (2018c). The Associations among Market Orientation, Technology Orientation, Entrepreneurial Orientation and Organizational Performance. Benchmarking: An International Journal, 25(8), 3117-3142.

Masa'deh, R., Hunaiti, Z., \& Bani Yaseen, A. (2008). An Integrative Model Linking ITBusiness Strategic Alignment and Firm Performance: The Mediating Role of Pursuing Innovation and Knowledge Management Strategies. Communications of the International Business Information Management Association (IBIMA) Journal, 2(24), 180-187.

Masa'deh, R., Gharaibeh, A., Tarhini, A., \& Obeidat, O. (2015a). Knowledge Sharing Capability: A Literature Review. 4th Scientific \& Research Conference on New Trends in Business, Management and Social Sciences (COES\&RJ-TK15/1), Istanbul, Turkey.

Masa'deh, R., Obeidat, B., Zyod, D., \& Gharaibeh, A. (2015b). The Associations among Transformational Leadership, Transactional Leadership, Knowledge Sharing, Job Performance, and Firm Performance: A Theoretical Model. Journal of Social Sciences (COES\&RJ-JSS), 4(2), 848-866.

Masa'deh, R., Almajali, D., Alrowwad, A., \& Obeidat, B. (2019a). The Role of Knowledge Management Infrastructure in Enhancing Job Satisfaction: A Developing Country Perspective. Interdisciplinary Journal of Information, Knowledge, and Management, 14, $1-25$.

Masa'deh, R., Obeidat, B., Maqableh, M., \& Shah, M. (2019b). The Impact of Business Intelligence Systems on an Organization's Effectiveness: The Role of Metadata Quality from a Developing Country's View. International Journal of Hospitality \& Tourism Administration, Forthcoming.

Mikkawi, B., \& Al-Lozi, M. (2017). The Impact of Knowledge Management Infrastructure on Academic Staff Effectiveness: An Empirical Study at The University of Jordan. Jordan Journal of Business Administration, 13(1), 95-127.

Obeidat, O., Al-Suradi, M., \& Tarhini, A. (2016). The Impact of Knowledge Management on Innovation: An Empirical Study on Jordanian Consultancy Firms. Management Research Review, 39(10), 1214-1238.

Obeidat, O., El-Rimawi, S., Maqableh, M., \& Al-Jarrah, I. (2013). Evaluating the Profitability of the Islamic Banks in Jordan. European Journal of Economics, Finance and Administrative Sciences, 56, 27-36.

Obeidat, O., Hadidi, A., \& Tarhini, A. (2017). Factors Affecting Strategy Implementation: A Case Study of Pharmaceutical Companies in the Middle East. Review of International Business and Strategy, 27(3), 386-408.

Obeidat, O., Tarhini, A., \& Aqqad, N. (2019). The Relationship among Emotional Intelligence, Conflict Management Styles, and Job Performance in Jordanian Banks. 
Journal of Business \& Management (COES\&RJ-JBM), 7(4), pp. 293-315

International Journal of Human Resources Development and Management, 19(3), 225265.

Obeidat, O., Sweis, R., Zyod, D., \& Alshurideh, M. (2012). The Effect of Perceived Service Quality on Customer Loyalty in Internet Service Providers in Jordan. Journal of Management Research, 4(4), 224-242.

Ramadan, E. (1998). Determinants of Innovative Behavior With an Application on Arab Academy for Science, Technology and Maritime Transport. The Advanced Management Institute, Alexandria, Egypt.

Robben, M.A. (1998). A Study of the Determinates of Individual Innovative Behavior in a High Technology Product Development Organization. Dissertation Abstract international. A 59/04, pp. 1252.

Robbins, S., \& David, A.D. (1998). Fundamentals of Management, Essential Concepts and Applications, ( $2^{\text {nd }}$ ed.) Upper Saddle Rivier, New Jersey: Pearson Education.

Roorda, N. (2001). Backcasting the Future. International Journal of Sustainability in Higher Education, 21(1), 44-72.

Rowe, L., \& Boise, B (1974). Organizational Innovation: Current Research and Evolving Concepts. Public Administration Review, 34(3), 285-287.

Scott, S., \& Reoinaid, A. (1994). Determinates of Innovation Behavior: Path Model of Individual Innovation in the Work Place. Academy of Management Journal, 37(3), 317325.

Shannak, R., \& Obeidat, B. (2012). Culture and the Implementation Process of Strategic Decisions in Jordan. Journal of Management Research, 4 (4), pp. 257-281.

Tarhini, A., Alalwan, A., Al-Qirim, N., \& Algharabat, R. (2018). An Analysis of the Factors Influencing the Adoption of Online Shopping. International Journal of Technology Diffusion (IJTD), 9(3), 68-87.

Tarhini, A., Al-Badi, A., Almajali, M., \& Alrabayaah, S. (2017a). Factors Influencing Employees' Intention to Use Cloud Computing. Journal of Management and Strategy, $8(2), 47$.

Tarhini, A., Al-Busaidi, K., Bany Mohammed, A., \& Maqableh, M. (2017b). Factors Influencing Students' Adoption of E-Learning: A Structural Equation Modeling Approach. Journal of International Education in Business, 10(2), 164-182.

Tarhini, A., Bany Mohammed, A., \& Maqableh, M. (2016). Modeling Factors Affecting Student's Usage Behaviour of E-Learning Systems in Lebanon. International Journal of Business and Management, 11(2), 299. 
Reviewing the Concept of Innovation and it relationship with Organizational ...

Tarhini, A., Mgbemena, C., \& Trab, MSA. (2015). User Adoption of Online Banking in Nigeria: A Qualitative Study. Journal of Internet Banking and Commerce, 20(3), 1-8.

Webster's New World college Dictionary (2004). New York: Merriam-Webster.

Yassien, E., \& Mufleh, M. (2017). The Impact of ERP System's Usability on Enterprise Resource Planning Project Implementation Success via the Mediating Role of User Satisfaction. Journal of Management Research, 9(3), 49-71. 